\title{
Progress Report on Graphite-Salt Intrusion Studies
}

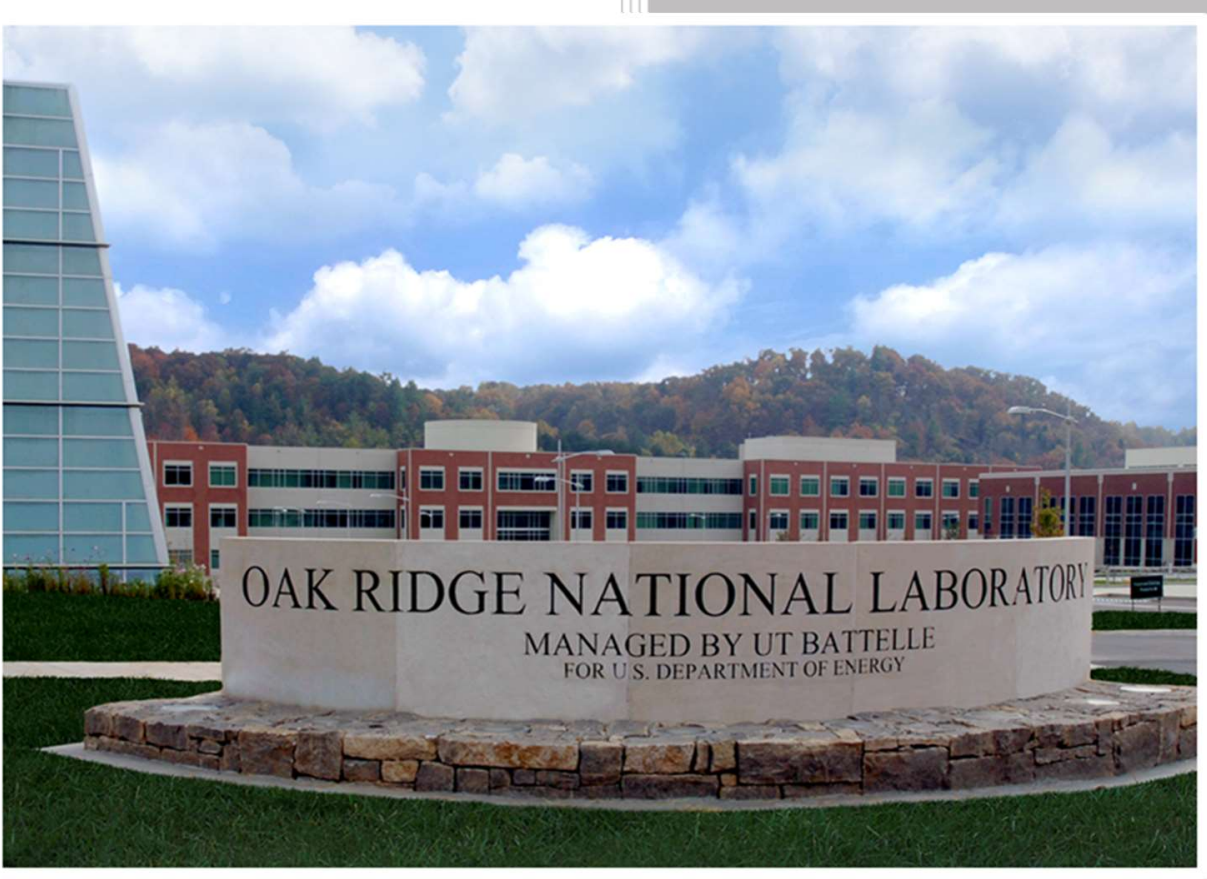

Nidia C. Gallego Cristian I. Contescu James R. Keiser

July 2020 


\section{DOCUMENT AVAILABILITY}

Reports produced after January 1, 1996, are generally available free via US Department of Energy (DOE) SciTech Connect.

Website www.osti.gov

Reports produced before January 1, 1996, may be purchased by members of the public from the following source:

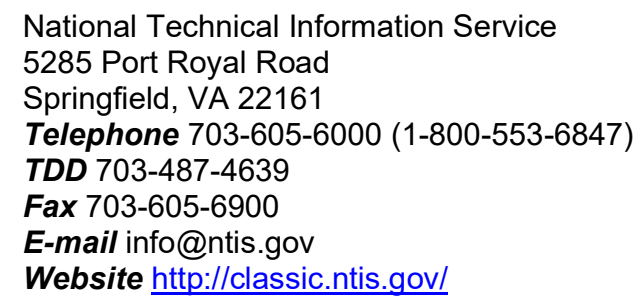

Reports are available to DOE employees, DOE contractors, Energy Technology Data Exchange representatives, and International Nuclear Information System representatives from the following source:

Office of Scientific and Technical Information

PO Box 62

Oak Ridge, TN 37831

Telephone 865-576-8401

Fax 865-576-5728

E-mail reports@osti.gov

Website http://www.osti.gov/contact.html

This report was prepared as an account of work sponsored by an agency of the United States Government. Neither the United States Government nor any agency thereof, nor any of their employees, makes any warranty, express or implied, or assumes any legal liability or responsibility for the accuracy, completeness, or usefulness of any information, apparatus, product, or process disclosed, or represents that its use would not infringe privately owned rights. Reference herein to any specific commercial product, process, or service by trade name, trademark, manufacturer, or otherwise, does not necessarily constitute or imply its endorsement, recommendation, or favoring by the United States Government or any agency thereof. The views and opinions of authors expressed herein do not necessarily state or reflect those of the United States Government or any agency thereof. 
Materials Science and Technology Division

\title{
PROGRESS REPORT ON GRAPHITE-SALT INTRUSION STUDIES
}

\author{
Nidia C. Gallego \\ Cristian I. Contescu \\ Jim Keiser
}

Date Published: July 2020

Prepared by

OAK RIDGE NATIONAL LABORATORY

Oak Ridge, TN 37831-6283

managed by

UT-BATTELLE, LLC

for the

US DEPARTMENT OF ENERGY

under contract DE-AC05-00OR22725 



\section{CONTENTS}

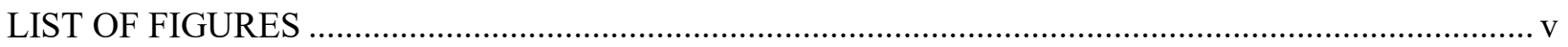

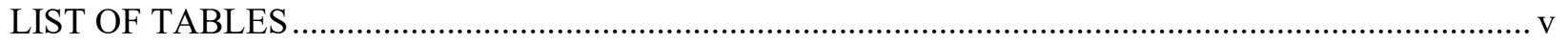

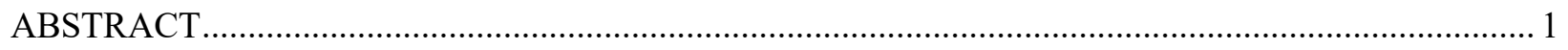

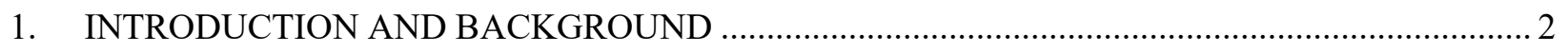

2. STANDARD GUIDE FOR THE IMPREGNATION OF GRAPHITE WITH MOLTEN

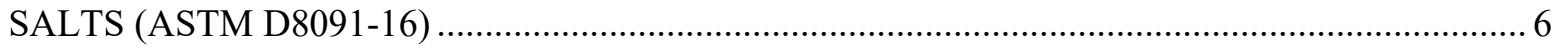

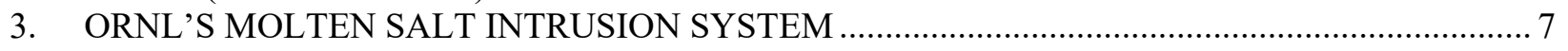

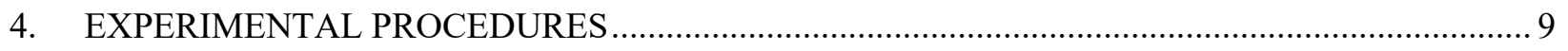

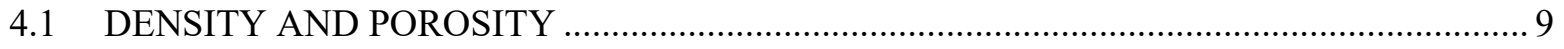

4.2 GRAPHITE POROSITY CHARACTERIZATION BY MERCURY INTRUSION ............... 10

4.3 PROCEDURE OF FLINAK IMPREGNATION TESTS ….............................................. 11

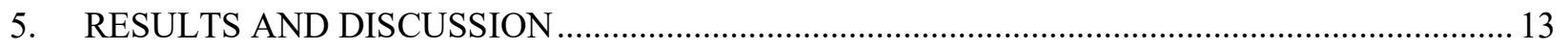

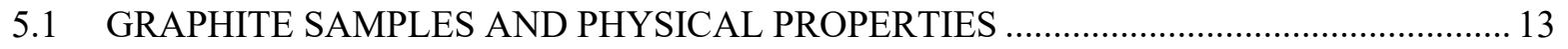

5.2 POROSITY CHARACTERIZATION FROM MERCURY POROSIMETRY ....................... 14

5.3 RESULTS FROM INTRUSION TESTING WITH MOLTEN FLINAK ….......................... 18

5.4 CORRELATION BETWEEN FLINAK IMPREGNATION AND MERCURY

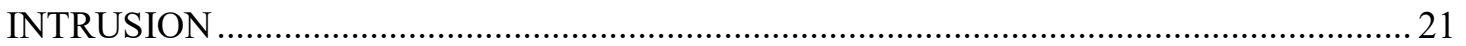

5.5 LIMITATIONS OF THE PREDICTIONS BASED ON MERCURY POROSIMETRY ........ 23

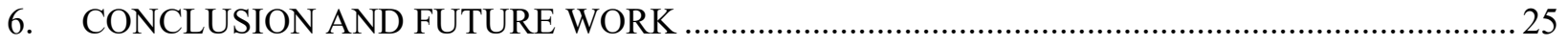





\section{LIST OF FIGURES}

Figure 1. Schematic and photo of ORNL's high-pressure salt infiltration rig........................................ 7

Figure 3. Optical image (polarized light) of manufactured graphite showing complex structure composed of filler, binder, and pores................................................................................... 9

Figure 4. Mercury porosimetry results showing intrusion volume during the increase and decrease of mercury pressure for fine graphite grades. ..................................................................... 15

Figure 5. Mercury porosimetry results showing intrusion volume during the increase and decrease of mercury pressure for medium and coarse graphite grades. ................................................ 16

Figure 6. Cumulative volume of mercury intrusion vs. mercury pressure for all graphite grades............. 17

Figure 7. Log differential pore volume vs. pore diameter for all graphite grades. ................................... 18

Figure 8 . Pore volume distribution of six graphite grades measured by mercury porosimetry: (left) cumulative pore volume vs. pore size; (right) log differential pore volume vs. pore size.

Figure 9. FLiNaK impregnation results from this study at $750^{\circ} \mathrm{C}$ and $798 \mathrm{kPa}$ for $12 \mathrm{~h}$ (large diamond symbols) compared with published data for FLiNaK impregnation at $650^{\circ} \mathrm{C}$ for $20 \mathrm{~h}$ up to $1,000 \mathrm{kPa}$ (adapted from $\mathrm{He}$ et al. ${ }^{47}$ ).

Figure 10. Predicted FLiNaK impregnation as a function of pressure at $750^{\circ} \mathrm{C}$ based on mercury porosimetry data.

\section{LIST OF TABLES}

Table 1. Physical properties of graphite grades characterized by pore analysis methods.....

Table 2. Results obtained from FLiNaK intrusion experiment at $750^{\circ} \mathrm{C}, 101 \mathrm{psig}(798 \mathrm{kPa})$, and $12 \mathrm{~h}$.

Table 3. Surface tension and contact angles for the graphite-mercury and graphite-FLiNaK systems. 



\begin{abstract}
The document reports on the design, construction, testing, and initial operations of the Oak Ridge National Laboratory graphite intrusion system with pressurized molten salts. This technical memorandum is in response to work package AT-20OR04060203, "Graphite-Salt Studies_-ORNL," and fulfills Milestone M3AT20OR040602035, "Report on graphite-salt intrusion studies."

The report outlines the procedure for graphite intrusion experiments, which follow the ASTM standard guidance, and the procedures of other characterization measurements of graphite physical properties, which are also based on ASTM standard methods. Twelve graphite grades of various origin and properties went through preliminary characterizations, and six were selected for intrusion experiments with molten FLiNaK. The results are discussed in the context of graphite physical properties and are compared with several results from literature. First proposed by MSRE scientists, the correlation between molten salt impregnation and mercury intrusion is discussed in detail. Pending the collection of more data, the mercury intrusion porosimetry technique could be used as a rapid method for screening and down-selecting graphite grades with extremely low salt intrusion, as required for operation in molten salt reactors.

This new system will generate not only data on intrusion behavior but also a wide range of saltimpregnated graphite samples that will be further analyzed with advanced characterization techniques to better understand the effect of salt intrusion on the properties of nuclear graphite. The results and future results obtained with this system are expected to help advance the understanding of factors that control the extent of salt penetration in graphite and the relationship with intrinsic structural properties of various grades. Together, correlating direct measurements results and graphite structural properties should allow a predictable model to be developed that could be used for the selection and qualification of optimal graphite grades, which are tailored to design-operation conditions and molten salt properties.
\end{abstract}




\section{INTRODUCTION AND BACKGROUND}

From 1965 to 1969, the Oak Ridge National Laboratory (ORNL) Molten Salt Reactor Experiment (MSRE) demonstrated that graphite can be used as a moderator in nuclear reactors in which molten fluoride salts are used both as a coolant and liquid fuel carrier. In the MSRE reactor, graphite was in direct contact with the fueled salt, which was the mixture of ${ }^{7} \mathrm{LiF}-\mathrm{BeF}_{2}-\mathrm{ZrF}_{4}-\mathrm{UF}_{4}(65.0-29.1-5.0-0.9$ mole \%), and with the nonfueled coolant, which was the ${ }^{7} \mathrm{LiF}_{-\mathrm{BeF}}$ eutectic (66-34 mole \%), also known as $F L i B e$. At the operating temperature $\left(650^{\circ} \mathrm{C}\right)$, the salt vapor pressure was less than $15 \mathrm{~Pa}$, and the gas blanket (He) pressure above the salt was $700 \mathrm{~Pa}^{1}{ }^{1}$ Graphite was the preferred choice for the moderator in contact with the molten salts due to its low wettability and better chemical corrosion resistance than most metals in molten fluoride salts.

The graphite grade used in the MSRE reactor was selected through a long process that was aimed at simultaneously meeting three requirements: $:^{1,2}$

1. Having a low intrusion of pressurized salt to avoid thermal stress and the development of hot points through the accumulation of fissionable material in the voids (i.e., cracks, pores) that naturally exist in nuclear graphite;

2. Having a low gas permeability to minimize retention of fission products in graphite, which-like ${ }^{135} \mathrm{Xe}$ - might trap neutrons and seriously perturb the neutronic balance; and

3. Having a high-density, isotropic, well-graphitized structure that would minimize structural damage and dimensional changes by fast neutron irradiation and maximize the lifetime of in-core components.

The MSRE team worked closely with graphite manufacturers to test many experimental graphite grades for conformity to the specification (e.g., degree of graphitization, chemical purity, thermal expansion, thermal conductivity, strength in flexure and tension, structural integrity, absence of cracks or faults). Most grades met these specifications but did not meet the low salt intrusion requirements. One MSRE requirement was that the volume of molten salt intrusion in graphite at $150 \mathrm{psi}$ and $700^{\circ} \mathrm{C}$ should be less than $0.5 \%$ of the total volume of graphite specimens. ${ }^{3}$ The tests were performed by achieving the direct impregnation of graphite specimens with hot, pressurized molten salts and recording the weight uptake; the volume percentage of intruded salt at the standard conditions was calculated from the density of molten salt at the respective temperature. ${ }^{3}$ These tests were laborious, slow, costly, and inconvenient because they used toxic salt materials at high temperatures and pressures. Only later, with the intensification of graphite development efforts, did the MRSE team recommended using mercury penetration measurements at room temperature as a faster alternative procedure for preselecting graphite materials that might meet the low-intrusion requirement in the standard tests with molten salts. ${ }^{4}$ At the time, only two graphite grades, CGB-X and B-1, were prequalified based on mercury intrusion tests, but CGB was selected after meeting the preferred qualification test or the direct impregnation by the molten salt.

${ }^{1}$ P. N. Haubenreich and J. R. Engel. "Experience with the Molten-Salt Reactor Experiment," Nuclear Applications and Technology 8 (1970): 118.

${ }^{2}$ W. P. Eatherly. "Graphite," in The Development of Molten-Salt Breeder Reactors, M. W. Rosenthal, P. N. Haubenreich, and R. B. Briggs. ORNL-4812 (1972): 175-193.

${ }^{3}$ R. B. Briggs. Molten-Salt Reactor Program Semiannual Progress Report for Period Ending February 28, 1962. ORNL-3282, Oak Ridge National Laboratory, July 11, 1962.

${ }^{4}$ R. B. Briggs, W. H. Cook, and A. Taboada. Modifications to Specifications for MSRE Graphite. CF-63-2-18, Oak Ridge

National Laboratory, February 14, 1963. 
The importance of molten salt infiltration studies in graphite was highlighted by recent reports ${ }^{5,6}$ related to the renewed interest in molten salt reactors (MSRs). The original MSR design had graphite in contact with two molten salt circuits: one containing the fuel and fission products and the other being a fuel-free coolant. In other designs, fuel pebbles containing tristructural-isotropic (TRISO) fuel microspheres circulate in molten fluoride salt. In this high-temperature fluoride (HFR) design, the carbon matrix in pebbles and graphite in the moderator and reflector are in contact with non-fuel fluoride salt, and the fission products are retained in the TRISO microspheres. Two types of fluoride salts are frequently studied as prototypes: ${ }^{7} \mathrm{LiF}_{-\mathrm{BeF}}$ (66-34 mole \%), also called FLiBe, and ${ }^{7} \mathrm{LiF}-\mathrm{NaF}-\mathrm{KF}$ (46.5-11.5-42 mole \%), also called FLiNaK.

Molten salt penetration in graphite could have significant negative consequences for reactor lifetime and safe operation, which are aggravated if graphite is in direct contact with fuel-containing molten salts. Research has focused on understanding the interaction mechanisms between molten fluoride components and graphite, as well as the effect on graphite properties essential for performance in MSR. Postexamination results of graphite used in MSRE showed that the concentration of $\mathrm{F}$ and Li infiltrated in graphite exposed to molten fuel salt decayed exponentially with distance from the graphite surface, but $\mathrm{F}$ and Li had concentrations that were two and one orders of magnitude, respectively, higher after 9 months of exposure in a reactor than in unirradiated graphite with the same exposure length in molten fluorides. ${ }^{7}$ According to recent results, $\mathrm{Na}$ and $\mathrm{K}$ ions (from $\mathrm{FLiNaK}$ ) have different migration rates under irradiation, which might result in unbalanced distribution and damage graphite coherence in moderator and reflector components. ${ }^{8}$ The solidification of salts in graphite's Mrozowski cracks could generate internal compression stress, which might increase the coefficient of thermal expansion and improve graphite crystalline stacking. ${ }^{9}$ Another report found that the mechanical strength of graphite impregnated under pressure in FLiNaK decreased with the weight gain increase. Because the compressive strength was more susceptible to salt infiltration than the tension strength, the failure mechanism changed from shear fracture to longitudinal splitting. ${ }^{10}$

In addition to physical interactions (i.e., ion diffusion from molten salt), chemical interactions might also affect graphite properties. At room temperature and pressure, graphite is inert toward dry fluorine gas, but graphite fluorination starts above $300^{\circ} \mathrm{C}$ and forms covalent graphite fluoride compounds. ${ }^{11}$ The deep penetration of fluorine from molten fluorides inside graphite is likely driven by local chemical interactions. ${ }^{12}$ Graphite fluorination could result in the local expansion of the graphite lattice, ${ }^{13}$ which might increase rhombohedral phase content and create defective sites that can retain fission byproducts,

${ }^{5}$ D. LeBlanc. "Molten Salt Reactors: A New Beginning for an Old Idea," Nucl Eng Design 240 (2010): 1,644-1,656.

${ }^{6}$ S. J. Zinkle and J. T. Busby. "Structural Materials for Fission and Fusion Energy," Materials Today 12 (2009): 12-19.

${ }^{7}$ R. L. Macklin, J. H. Gibbons, E. Ricci, T. Handley, and D. Cuneo. "Proton Reaction Determination of Lithium and Fluorine in Molten Salt Reactor Graphite,” Nuclear Applications 5 (1968): 269-274. doi:10.13182/NT68-A28030.

${ }^{8}$ Q. Lei Z. He, W. Qi, H. Tang, J. Zeng, Q. Deng, C. Zhang, N. Guo, H. Zhang, Y. Zhang, H. Shen, and X. Zhou. "IrradiationInduced Mixing of $\mathrm{Na}$ and $\mathrm{K}$ in Graphite in Molten Salt Reactor: An Estimation Based on Ion Beam Irradiation," Nucl Inst and Methods in Phys Res B 450 (2019): 100-107.

${ }^{9}$ Z. He, L. Gao, X. Wang, B. Zhang, W. Qi, J. Song, X. He, C. Zhang, H. Tang, H. Xia, and X. Zhou. "Improvement of Stacking Order in Graphite by Molten Fluoride Salt Infiltration," Carbon 72 (2014): 304-311.

${ }^{10}$ C. Zhang, Z. He, Y. Gao, H. Tang, Q. Qi, J. Sing, and X. Zhou. "The Effect of Molten FLiNaK Salt Infiltration on the Strength of Graphite," J Nucl Mater 512 (2018): 37-45.

${ }^{11}$ A Hamwi. "Fluorine Reactivity with Graphite and Fullerenes. Fluoride Derivatives and Some Practical Electrochemical Applications," J Phys Chem Solids 57 (1996): 677-688.

${ }^{12} \mathrm{H}$. Wu, F. Carotti, R. Gakhar, N. Patel, and R. O. Scarlat. "Fluorination of Nuclear Graphite IG-110 in Molten 2LiF-BeF 2 (FLiBe) Salt at $700^{\circ} \mathrm{C}, " J$ Fluorine Chem 211 (2018): 159-170.

${ }^{13}$ X. Yang, S. Feng, X. Zhou, H. Xu, and T. K. Sham. "Interaction between Nuclear Graphite and Molten Salts: A Synchrotron Radiation Study of the Substitution of Graphitic Hydrogen by Fluoride Ion," J Phys Chem A 116 (2012): 985-989. 
such as tritium. ${ }^{14}$ Trapped in core graphite components, tritium could create serious decontamination problems in the reactor's decommissioning stage.

Many strategies have been proposed to reduce molten salt penetration and gaseous product permeation in nuclear graphite, and they can be grouped in two categories: (1) the bulk densification and surface sealing of medium- and fine-grain graphites and (2) the development of new microfine- and superfine-grain graphites tailored for nuclear applications. In the first category, graphite impregnation with hydrocarbons (e.g., pitch, furans) or resin precursors (e.g., polyfurfuryl alcohol, phenolic resins) has led to a generally acceptable impregnation procedure with pitch; this procedure was used to fabricate the CGB graphite bars used in the MSRE. ${ }^{15}$ More graphite development studies published in recent years reported impregnation experiments with phenolic resin ${ }^{16}$ and surface sealing by pyrolytic carbon, ${ }^{15,17,18,19}$ glassy carbon,${ }^{20}$ silicon carbide, ${ }^{21,22}$ or combinations thereof. ${ }^{23}$ Early attempts within the MSRE program to obtain compact graphite bodies by manipulating the grain size and nature of raw materials ${ }^{15}$ belong to the second category. Newer reports emerged regarding the fabrication of binderless nanopore isotropic graphite 24,25 and fine-grain ${ }^{26,27}$ and ultrafine-grain graphite ${ }^{28}$ that use various fillers and dispersion techniques. According to these reports, graphite pore sizes can be manipulated down to submicron values as needed for operation in molten salts. However, there is currently very little information on the suitability of these new or modified graphite materials for use in nuclear reactors. The long-term effects of exposure to pressurized molten salts, high temperatures, and intense neutron irradiation must be characterized in the qualification process of graphite grades for MSR applications.

${ }^{14} \mathrm{H}$. Wu, F. Carotti, R. Gakhar, N. Patel, and R. O. Scarlat. "Fluorination of Nuclear Graphite IG-110 in Molten 2LiF-BeF 2 (FLiBe) Salt at $700^{\circ} \mathrm{C}$," J Fluorine Chem 211 (2018): 159-170.

${ }^{15}$ M. W. Rosenthal, R. B. Briggs, and P. N. Haubenreich. Molten Salt Reactor Program Semiannual Progress Report for Period Ending August 31, 1972. ORNL-4832, Oak Ridge National Laboratory, March 1973.

${ }^{16}$ Z. He, P. Lian, Y. Song, Z. Liu, J. Song, J. Zhang, J. Feng, X. Yan, and Q. Guo. "Improving Molten Fluoride Salt and Xe ${ }^{135}$ Barrier Property of Nuclear Graphite by Phenolic Resin Impregnation Process," J Nucl Mater 499 (2018): 79-87.

${ }^{17}$ X. He, K. Song, L. Xu, J. Tan, H. Xia, B. Zhang, Z. He, L. Gao, X. Zhou, M. Zhao, Z. Zhu, and Z. Bai. "Protection of Nuclear Graphite Toward Liquid Fluoride Salt by Isotropic Pyrolytic Coating," J Nucl Mater 442 (2013): 306-308.

${ }^{18}$ S. Feng, L. Xu, L. Li, S. Bai, X. Yang, and Z. Zhou. "Sealing Nuclear Graphite with Pyrolytic Carbon," J Nucl Mater 441 (2013): 449-454.

${ }^{19}$ J. Song, Y. Zhao, X. He, B. Zhang, L. Xu, Z. He, D.-S. Zhang, L. Gao, H. Xia, X. Zhou, P. Huai, and S. Bai. "Preparation of Pyrolytic Carbon Coating on Graphite for Inhibiting Liquid Fluoride Salt and Xe ${ }^{135}$ Penetration for Molten Salt Breeder Reactor," J Nucl Mater 456 (2015): 33-40.

${ }^{20}$ V. Bernardet, S. Gomes, S. Delpeux, M. Dubois, K. Guerin, D. Avignant, G. Renaudin, and L. Duclaux. "Protection of Nuclear Graphite towards Fluoride Molten Salt by Glassy Carbon Deposit,” J Nucl Mater 384 (2009): 292-302.

${ }^{21}$ X. He, J. Song, J. Tan, B. Zhang, H. Xiam Z. He, X. Zhou, M. Zhao, X. Liu, L. Xu, and S. Bai. "SiC Coating: An Alternative for the Protection of Nuclear Graphite from Liquid Fluoride Salt," J Nucl Mater 448 (2014): 1-3.

${ }^{22}$ Z. He, P. Lian, Y. Song, Z. Liu, J. Song, J. Zhang, X. Ren, J. Feng, X. Yan, Q. Guo, and W. Liu. "Protecting Nuclear Graphite from Liquid Fluoride Salt and Oxidation by SiC Coating Derived from Carbosilane," J European Ceramic Soc 38 (2018): $453-$ 462 .

${ }^{23}$ Z. He, J. Song, P. Lian, D. Zhang, and Z. Liu. "Excluding Molten Fluoride Salt from Nuclear Graphite by SiC/Glassy Carbon Composite Coating," Nucl Eng Technol 51 (2019): 1,390-1,397.

${ }^{24}$ J. Song, Y. Zhao, J. Zhang, X. He, B. Zhang, P. Lian, Z. Liu, D. Zhang, Z. He, L. Gao, H. Xia, Z. X. Zhou, P. Huai, Q. Guo, and L. Liu. "Preparation of Binderless Nanopore-Isotropic Graphite for Inhibiting Liquid Fluoride Salt and Xe ${ }^{135}$ Penetration for Molten Salt Nuclear Reactor," Carbon 79 (2014): 36-45.

${ }^{25}$ H. Zhao, Z. He, Z. Liu, J. Song, D. K. L. Tsang, and H. Zhang. "Self-Sintered Nanopore-Isotropic Graphite Derived from Green Pitch Coke for Application in Molten Salt Nuclear Reactor," Annals Nucl Energy 131 (2019): 412-416.

${ }^{26}$ Z. He, P. Lian, J. Song, D. Zhang, Z. Liu, and Q. Guo. "Microstructure and Properties of Fine-Grained Isotropic Graphite Based on Mixed Fillers for Application in Molten Salt Breeder Reactor," J Nucl Mater 511 (2018): 318-327.

${ }^{27}$ Z. He, Z. Liu, J. Song, .P Lian, and Q. Guo "Fine-Grained Graphite with Super Molten Salt Barrier Property Produced from Filler of Natural Graphite Flake by a Liquid-Phase Mixing Process," Carbon 145 (2019): 367-377.

${ }^{28}$ P. Lian, J. Song, Z. Liu, J. Zhang, Y. Zhao, Y. Gao, Z. Tao, Z. He, L. Gao, H. Xia, Q. Guo, P. Huai, and X. Zhou. "Preparation of Ultrafine-Grain Graphite by Liquid Dispersion Technique for Inhibiting the Liquid Fluoride Salt Infiltration," Carbon 102 (2016): 208-215. 
This report documents ORNL's efforts to directly measure molten salt impregnation in graphite as an important component of the graphite selection and qualification process. For this effort, ORNL designed and built an experimental High-Pressure Salt Infiltration Rig as part of the MSR campaign within the Advanced Reactor Technology program. Details of the ASTM guideline and ORNL's test rig are presented, followed by a detailed characterization of graphite porosity by various techniques, including mercury intrusion. The results of the FLiNaK intrusion tests and their correlation with mercury intrusion results are also presented and discussed. The concluding section outlines the significance of the results, lists unanswered questions, and makes suggestions for future work. 


\section{STANDARD GUIDE FOR THE IMPREGNATION OF GRAPHITE WITH MOLTEN SALTS (ASTM D8091-16)}

In 2016, ASTM International (formerly the American Society for Testing and Measurements) adopted the Standard Guide for Impregnation of Graphite with Molten Salt, Designation D8091-16. ${ }^{29}$ The guide outlines the procedure for the impregnation of graphite with molten salt under a consistent pressure and temperature. This procedure can be used to prepare graphite specimens for testing that were exposed to a molten salt environment and might not necessarily represent material exposed to an operating reactor environment.

The details of the procedure will not be transcribed here. However, the authors want to highlight the parameter $\mathrm{D}$, as defined in the guide, which provides a measure of the extent of penetration of the graphite porosity by the molten salt. Two situations are considered in the guide. If the pressure used for impregnation is such that no damage to the microstructure of the graphite is expected during the test, then parameter $D_{0}$ is calculated based on open-pore volume and would be unity at saturation. However, $D_{0}$ can be greater than 1 when the molten salt impregnation occurs at high pressure. In this situation, it is postulated that the internal microstructure of graphite has been damaged by the impregnation pressure and that some closed pores have been opened. In that case, the parameter $D_{l}$ should be calculated based on the total open- and closed-pore volume.

$$
\begin{aligned}
& D_{0}=\frac{w_{2}-w_{1}}{\rho V_{0}}, \\
& D_{1}=\frac{w_{2}-w_{1}}{\rho V_{t}},
\end{aligned}
$$

where $w_{1}$ is the sample weight before impregnation, $w_{2}$ is the sample weight after impregnation, $\rho$ is the density of molten salt, $V_{0}$ is the volume of open pores in the sample, and $V_{t}$ is the total volume of open and closed pores in the sample.

The total pore volume and open-pore volume can be calculated from the physical properties of the sample, including weight, bulk density, skeleton density, and graphite crystal density. Details of these calculations and procedures are presented in Section 4.

${ }^{29}$ ASTM D8091-16, Standard Guide for Impregnation of Graphite with Molten Salt. ASTM International, 2016. 


\section{ORNL'S MOLTEN SALT INTRUSION SYSTEM}

ORNL completed the design, assembly, and commissioning testing of the experimental system to expose graphite samples to molten salt at elevated pressures. The system was designed for operation at temperatures up to $750^{\circ} \mathrm{C}$ and pressures up to $10 \mathrm{bar}$ (the MSR pressure range of interest is 10 bar or less), and it closely follows most of the guidance provided in ASTM D8091-16.

The ORNL system (Figure 1) uses a vertically oriented three-zone clamshell 5 in. inner diameter furnace, and each zone measures 4 in. tall. The salt-containment vessel has a $\sim 4.5 \mathrm{in}$. diameter and is $16 \mathrm{in}$. tall; it is fabricated from an alloy $800 \mathrm{H} 4$ in. pipe and has a plate welded to the bottom and a 24 bolt flange welded to the top. A graphite liner, which extends the full height of the salt-containment vessel, is located within the containment vessel to contain the salt so that the salt is only in contact with graphite components; nothing metallic touches the salt. The salt-containment vessel is supported in the furnace so that the bottom of the vessel is almost at the bottom of the lowest zone of the furnace. This allows heat to be concentrated on the bottom of the vessel where the salt is located while keeping the top flange of the vessel somewhat cooler.
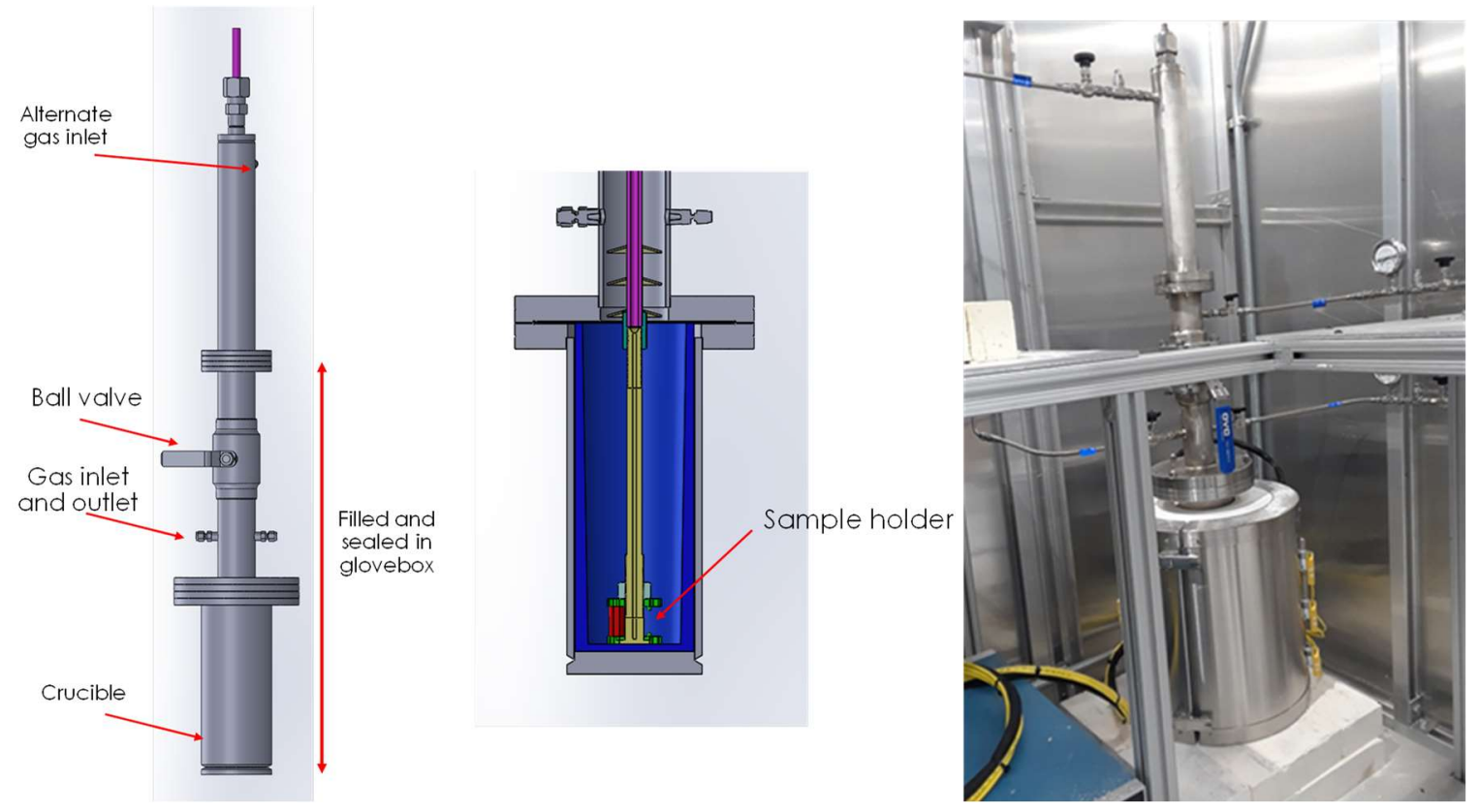

Figure 1. Schematic and photo of ORNL's high-pressure salt infiltration rig.

Above the primary salt-containment vessel is a smaller diameter pipe intended for sample containment, and it is welded to a flange that mates with the flange on top of the salt-containment vessel. This pipe is sized so that it provides sufficient clearance for the sample holder but is not larger than necessary since it will be exposed to the same pressure as the vessel that contains the molten salt. A full port ball valve near the bottom of this sample containment section allows for isolation of sample holder and samples from the environment above the molten salt.

The piping system allows argon to be introduced to the system at two locations: (1) the pressure vessel that contains the molten salt and (2) the upper sample chamber when the ball valve is separating the vessel and chamber is closed. The supply lines to both sections include pressure relief valves. Both the vessel and chamber have outlet lines, and the outlet line on the sample chamber has connections for a 
pressure transducer, pressure gauge, vacuum pump fitting, and backpressure control valve. Valving allows the evacuation of the sample chamber or both the sample chamber and the salt-containment vessel.

The current ORNL system includes an all-graphite holder that can accommodate up to six samples, which are typically $\sim 1.27 \mathrm{~cm}$ wide and deep and on the order of $2.5 \mathrm{~cm}$ tall. The sample holder can accommodate samples with smaller dimensions or cylindrical samples. The first and second generations of the sample holders are shown in Figure 2. The all-graphite sample holder is designed so that the vertical surfaces of the samples are freely exposed to the molten salt. Molten salt has restricted access to the limited portion of the horizontal surfaces that are in contact with the sample holder, but prudently located holes in the horizontal components of the sample holder provide salt access to most horizontal sample surfaces. The graphite support rod that is part of the sample holder is attached to a metal rod through a threaded connection; the graphite support rod is long enough that the metal rod stays well above the molten salt and should not have an effect on the salt or the samples. The graphite support rod is closed on the "bottom" end adjacent to the graphite samples, and a central hole along the axis of the metal rod and the graphite sample support rod provides access for a thermocouple that is used to monitor the salt temperature when the samples are immersed in the salt.

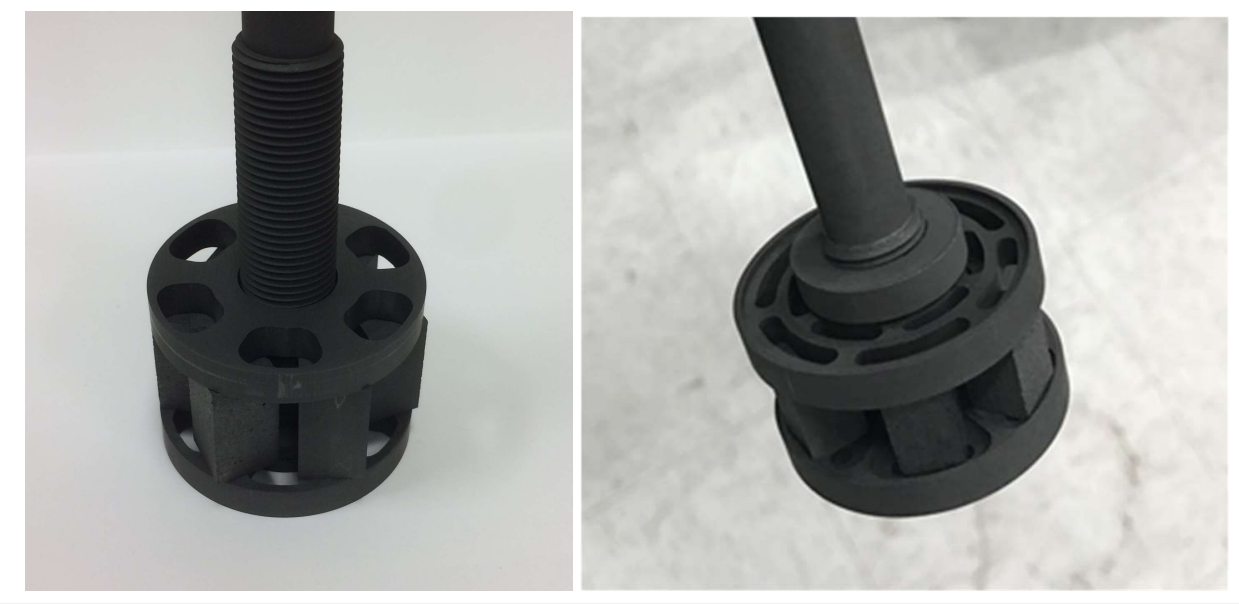

Figure 2. First- and second-generation graphite sample holder.

The valving arrangement allows the samples to be held in a vacuum while the salt is melted under an argon atmosphere. Once the salt reaches the desired temperature, the pressure around the samples is rapidly increased to one atmosphere (argon), then the samples are lowered into the molten salt. Once the samples are in the salt, the pressure is increased to the desired level, and the salt and sample temperatures are equilibrated at the desired level.

Once the exposure time is reached, the samples are raised a short distance above the molten salt while still under pressure. Although the pressure is maintained, the furnace is turned off, and the salt pool and the salt that infiltrated the graphite samples are allowed to solidify. Once the samples are cooled close to room temperature, the pressure is reduced to slightly above atmospheric pressure. The samples are raised sufficiently high so that the large ball valve can be closed, thus isolating the solidified salt pool from the samples. This allows an inert atmosphere to be maintained over the solidified salt while the sample chamber is removed. Once the sample chamber is removed, the samples are removed from the sample holder as quickly as possible, any loose salt is brushed off, and the samples are inserted into the glovebox antechamber, which is then evacuated. When the samples can be introduced into the glovebox, they are weighed and stored for further studies. 


\section{EXPERIMENTAL PROCEDURES}

\subsection{DENSITY AND POROSITY}

Nuclear graphite is a composite material, and its main components are two solid phases-filler particles and binder phase - and a system of void volumes, as shown in Figure 3. The most used filler materials are petroleum cokes and coal-tar pitch-derived cokes. The morphology, size, shape, and structure of filler particles are the primary factors that determine graphite properties. Graphite manufacturing starts with mixing the binder material, typically a coal-tar pitch, with previously calcined and crushed filler particles. The obtained mix is shaped by various methods (e.g., extrusion, vibrationally molding, isostatically pressing) to form the green body, followed by various cycles of baking $\left(800-1,000^{\circ} \mathrm{C}\right)$, densification (i.e., impregnation with binder), and finally graphitization at high temperatures $\left(2,500-3,000^{\circ} \mathrm{C}\right) .{ }^{30}$

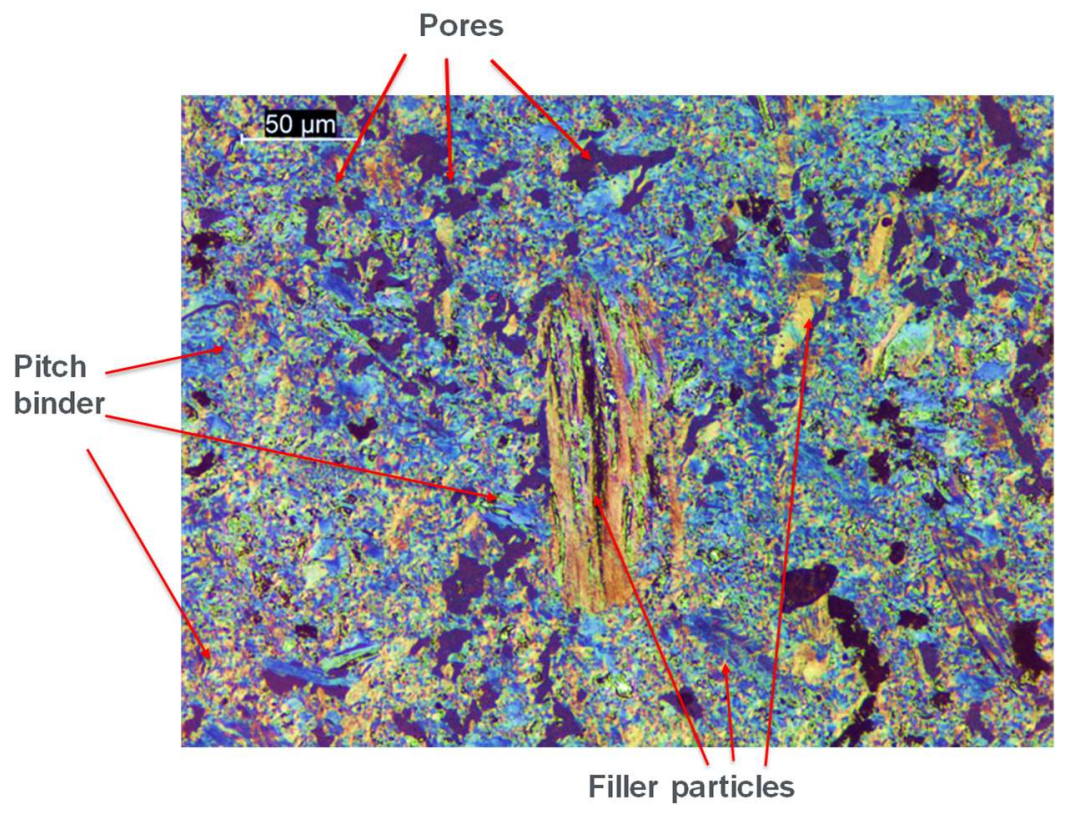

Figure 3. Optical image (polarized light) of manufactured graphite showing complex structure composed of filler, binder, and pores.

Typical bulk density values of manufactured graphite vary from 1.70 to $1.90 \mathrm{~g} \mathrm{~cm}^{-3}$, which is lower than the crystallographic density of graphite $\left(2.24 \mathrm{~g} \mathrm{~cm}^{-3}\right)$. The difference is attributed to the system of void volumes (i.e., pores) distributed throughout the graphite structure, which are packing voids incompletely filled by the binder phase, gas entrapped in the binder formed during pyrolysis and graphitization, or thermal cracks formed by anisotropic shrinkage of filler coke and binder crystals. Graphite porosity is a mixture of interconnected pores, which are either open and accessible to the surface or closed and inaccessible to the surface. ${ }^{30}$

Two different density definitions can be related to the complex structure of manufactured graphite: bulk and skeletal density.

${ }^{30}$ T. D. Burchell. "Graphite: Properties and Characteristics," in Comprehensive Nuclear Materials, ed. T. R. Allen, R. E. Stoller, and S. Yamanaka (Elsevier, 2011), 2: 285-305. 
ASTM C559-16 $6^{31}$ defines bulk density as the mass of a unit volume of material, including both permeable and impermeable voids present in the material at room temperature. In this definition, permeable and impermeable voids refer to open and closed pores. To measure the bulk density per the ASTM method, the graphite samples were machined as rectangular parallelepiped bodies with clean and chip-free faces, corners, and edges. Before measuring, the samples were dried in an oven for $2 \mathrm{~h}$ at $100^{\circ} \mathrm{C}$ and cooled in a desiccator. The specimens were weighed to an accuracy of $0.05 \%$, and their dimensions were measured to an accuracy of $0.05 \%$. The bulk density was then calculated as the ratio between mass and volume.

Skeletal density is defined as the ratio of the mass of discrete pieces of solid material to the sum of the volumes of the solid material in the pieces, including closed pores within the pieces. There is not an ASTM standard method for measuring the skeletal density of carbon and graphite materials; however, the general principles of ASTM B923-16 ${ }^{32}$ for measurement of skeletal density of metal powders can be applied to machined graphite bodies. The method is based on measuring the gas volume that is totally displaced by the sample's skeletal volume. Calculations are based on ideal gas laws. The solid skeletal density is obtained as the ratio between the mass of the outgassed sample measured to the nearest $0.1 \mathrm{mg}$ and the volume of displaced gas. Before measuring, the sample is outgassed by a vacuum purge to empty the open pores and remove moisture and physically adsorbed gas. Helium gas is used for initial instrument calibration by using solid reference samples of known, calibrated volumes and for measurements. Multiple measurements are taken for each sample to achieve a stable value of the preselected standard deviation target. For this study, a Quantachrome Ultrapycnometer 1000 was used. A large sample cell $\left(9.7639 \mathrm{~cm}^{3}\right)$ was selected to fit the graphite samples. Calibration was done with a large added standard volume $\left(8.0608 \mathrm{~cm}^{3}\right)$ by using pure helium gas at a target pressure of $18.0 \mathrm{psi}(124,105$ $\mathrm{Pa})$. A rough vacuum $(15 \mathrm{~min})$ was applied to the samples before testing. The number of runs varied between 10 and 25 as needed to minimize the variations between successive runs.

After the sample densities are measured, the total volume of open and closed pores $\left(V_{t}\right)$ and the volume of open pores $\left(V_{0}\right)$ in the graphite sample with mass $(m)$ can be calculated by comparing specimen bulk density $\left(\rho_{\text {bulk }}\right)$ with either the skeleton density $\left(\rho_{\text {sk }}\right)$ measured by helium pycnometry or with the crystallographic density of graphite $\left(2.24 \mathrm{~g} / \mathrm{cm}^{3}\right)$ as follows:

$$
\begin{aligned}
& V_{0}=m\left(\frac{1}{\rho_{\text {bulk }}}-\frac{1}{\rho_{s k}}\right), \\
& V_{t}=m\left(\frac{1}{\rho_{\text {bulk }}}-\frac{1}{2.24}\right) .
\end{aligned}
$$

The closed-pore volume is given by the difference between the total volume and the open-pore volume.

\subsection{GRAPHITE POROSITY CHARACTERIZATION BY MERCURY INTRUSION}

Pressure-driven mercury intrusion is an established technique for porosity characterization in solid materials, and it is largely applied to building materials, ceramics, rocks, and geological specimens. ${ }^{33}$ The technique relies on capillarity theories and applies the Washburn ${ }^{34}$ equation that correlates the pressure differential $(P)$ required to push a fluid into a capillary tube (assumed right cylinders) of diameter $(d)$ with the fluid properties, namely surface tension $(\gamma)$ and wetting angle $(\theta)$ at the solid-liquid interface:

\footnotetext{
${ }^{31}$ ASTM C559-16, Standard Test Method for Bulk Density by Physical Measurements of Manufactured Carbon and Graphite Articles. ASTM International, 2016.

${ }^{32}$ ASTM B923-16, Standard Test Method for Metal Powder Skeletal Density by Helium or Nitrogen Pycnometry. ASTM International, 2016.

${ }^{33}$ H. L. Ritter and L. C. Drake. "Pore Size Distribution in Porous Materials," Ind. Eng. Chem. 17 (1945): 782.

${ }^{34}$ E. W. Washburn "The Dynamics of Capillary Flow," Phys Rev 17 (1921): 273-283.
} 


$$
P=\frac{4 \gamma}{d} \cos \theta
$$

For non-wetting liquids $\left(90^{\circ}<\theta<180^{\circ}\right)$, gradually larger capillary pressure $(P)$ is required to force the liquid through gradually narrowing pore openings $(d)$. The wetting parameters $\gamma$ and $\theta$ are specific to each fluid-solid material combination and can be estimated from separate measurements under well-controlled conditions, such as temperature and solid surface composition.

Mercury porosimetry measurements were performed by the Particle Technology Laboratory (PTL), a specialized contract laboratory in Downers Grove, Illinois. PTL followed the procedure described in ASTM D4284-12 (reapproved 2017) ${ }^{35}$ and used a Micromeritics Autopore IV 9500 instrument (i.e., penetrometer).

Graphite specimens were machined as cylinders $(22 \mathrm{~mm}$ tall $\times 10 \mathrm{~mm}$ diameter, $\sim 3.2 \mathrm{~g}$ each $)$ and engraved for identification. Before analysis, samples were outgassed for $30 \mathrm{~min}$ at $150^{\circ} \mathrm{C}$ to remove moisture and were then loaded in an appropriately sized sample holder. Conditioning continued in the penetrometer by evacuation to about $13 \mu \mathrm{m} \mathrm{Hg}(1.7 \mathrm{~Pa})$ and holding for $5 \mathrm{~min}$ at that pressure. The first mercury pressure point was at $0.98 \mathrm{psia}(6.75 \mathrm{kPa})$. Mercury intrusion analysis continued by raising the pressure at a rate of $50 \mu \mathrm{L} \mathrm{g}^{-1} \mathrm{~s}^{-1}$ up to the maximum pressure of 50,000 psia (344.7 MPa), which corresponds to the smallest pores ( $5 \mathrm{~nm}$ diameter) that can be analyzed by mercury intrusion. At each pressure, the mercury level variation above the sample was used to calculate the intruded volume. After reaching the maximum intrusion pressure, an extrusion run was performed down to a pressure of 20 psia $(138 \mathrm{kPa})$.

Data analysis is based on the Washburn equation (Eq. 5) by using the appropriate parameters ${ }^{35}$ for the graphite-mercury system: $\gamma=0.484 \mathrm{~N} / \mathrm{m}$ at $25^{\circ} \mathrm{C}$ and $\theta=155^{\circ}$. The results allow the calculation of the equivalent cylindrical pore diameter penetrated by mercury as a function of intrusion pressure. The range of pore diameters usually measured by mercury porosimetry is extremely broad, roughly $0.004-200 \mu \mathrm{m}$. By using the Washburn equation, these data are converted in the distribution of pore volumes vs. the diameter of pore openings from largest to smallest as the pressure increases. This information can also be used to determine cumulative and differential intrusion volume as a function of applied pressure.

\subsection{PROCEDURE OF FLINAK IMPREGNATION TESTS}

Graphite samples for salt infiltration were machined as right parallelepiped bodies. Each specimen was engraved with a unique code to maintain traceability in the process. The specimens were dried in air at $110^{\circ} \mathrm{C}$ for $2 \mathrm{~h}$ before physical measurements (e.g., dimensions, weight, density). After measurements, the specimens were stored in desiccators for future use.

To prepare for intrusion testing, all graphite samples and components, including the sample holder and graphite rod, were outgassed under high vacuum at $1,200^{\circ} \mathrm{C}$ for $8 \mathrm{~h}$. After outgassing, the assembled holder and samples were loaded into the intrusion system, and the samples were lowered to just above the ball valve, keeping the ball valve closed. After the system was sealed, a rough vacuum was applied to the samples overnight, and the pressure vessel containing the graphite crucible with the salt was gradually heated to the desired temperature under a blanket of flowing argon. Once the target temperature was reached and equilibrated, the valve ball was opened to allow the holder with samples to be lowered into the molten salt. The cover argon gas pressure was then raised to the desired testing pressure. Once this pressure was achieved, it was kept constant for $12 \mathrm{~h}$. The samples were then raised above the molten salt, and the system was allowed to cool overnight while maintaining the argon pressure. Once the system was

\footnotetext{
${ }^{35}$ ASTM D4284-12 (2017) Standard Test Method for Determining Pore Volume Distribution of Catalysts by Mercury Intrusion Porosimetry (ASTM International, 2017).
} 
at room temperature, the argon pressure was reduced to $\sim 1$ bar, and the holder with samples were raised to just above the ball valve. The ball valve was then closed, and the argon blanket protected the salt. The top part was carefully removed from the system, and graphite samples were quickly transferred to an argon glovebox for weighing and storage. Removing samples from the holder was sometimes difficult due to the solidification of residual salt around samples. 


\section{RESULTS AND DISCUSSION}

\subsection{GRAPHITE SAMPLES AND PHYSICAL PROPERTIES}

Twelve graphite grades were selected for physical measurement and analysis by mercury intrusion. These graphite grades covered a wide range of properties and microstructures, as listed in Table 1. One feature of interest for salt impregnation behavior is the grain size. As shown in Table 1, the grain size of the selected graphite grades varies from $1 \mu \mathrm{m}$ to $1.6 \mathrm{~mm}$. This property was crucial to the size of residual pore openings, namely those pores that might not have been fully infiltrated by the binder during the densification cycles.

Table 1. Physical properties of graphite grades characterized by pore analysis methods.

\begin{tabular}{|c|c|c|c|c|c|c|c|c|c|}
\hline $\begin{array}{c}\text { Graphite } \\
\text { grade }\end{array}$ & Classification $^{(a)}$ & $\begin{array}{c}\text { Grain } \\
\text { size }^{(b)} \\
(\mu \mathrm{m})\end{array}$ & $\begin{array}{c}\text { Bulk } \\
\text { density } \\
\left(\mathbf{g} \cdot \mathbf{c m}^{-3}\right)\end{array}$ & $\begin{array}{c}\text { Skeleton } \\
\text { density }^{(\mathrm{d})} \\
\left(\mathbf{g} \cdot \mathbf{c m}^{-3}\right)\end{array}$ & $\begin{array}{c}\text { Open } \\
\text { pores } \\
\text { volume } \\
\left(\mathbf{c m}^{3} \cdot \mathbf{g}^{-1}\right)\end{array}$ & $\begin{array}{c}\text { Closed } \\
\text { pores } \\
\text { volume } \\
\left(\mathrm{cm}^{\mathbf{f}} \cdot \mathbf{g}^{-1}\right)\end{array}$ & $\begin{array}{c}\text { Total } \\
\text { pores } \\
\text { volume } \\
\left(\mathbf{c m}^{3} \cdot \mathbf{g}^{-1}\right)\end{array}$ & $\begin{array}{c}\text { Porosity }^{(\mathrm{h})} \\
(\%)\end{array}$ & $\begin{array}{c}\text { Pore } \\
\text { diameter }^{(i)} \\
(\mu \mathrm{m})\end{array}$ \\
\hline $\begin{array}{l}\text { POCO } \\
\text { ZXF-5Q }\end{array}$ & microfine & 1 & 1.80 & 2.12 & 0.083 & 0.026 & 0.109 & 20 & 0.5 \\
\hline $\begin{array}{l}\text { POCO } \\
\text { AXF-5Q }\end{array}$ & ultrafine & 5 & 1.73 & 2.10 & 0.102 & 0.030 & 0.131 & 23 & 0.9 \\
\hline $\begin{array}{l}\text { POCO } \\
\text { TM }\end{array}$ & superfine & 10 & 1.73 & 2.10 & 0.102 & 0.030 & 0.132 & 23 & 2 \\
\hline IG-110 & superfine & 10 & 1.76 & 2.05 & 0.079 & 0.041 & 0.120 & 21 & 3.9 \\
\hline 2114 & superfine & 13 & 1.81 & 2.08 & 0.071 & 0.034 & 0.105 & 19 & 3.5 \\
\hline ETU-10 & superfine & 15 & 1.74 & 2.10 & 0.098 & 0.031 & 0.129 & 22 & 3.6 \\
\hline NBG-25 & fine & 60 & 1.81 & 2.07 & 0.068 & 0.038 & 0.105 & 19 & 5.1 \\
\hline CGB & medium-fine & $\mathrm{n} / \mathrm{a}$ & 1.86 & 1.87 & 0.003 & 0.089 & 0.091 & 17 & 0.2 \\
\hline PGX & medium-fine & 460 & 1.76 & 1.95 & 0.055 & 0.067 & 0.122 & 22 & 5.6 and 30 \\
\hline NBG-17 & medium-fine & 800 & 1.85 & 2.01 & 0.042 & 0.051 & 0.093 & 17 & $\begin{array}{c}3,12, \text { and } \\
51\end{array}$ \\
\hline PCEA & medium-fine & 800 & 1.77 & 2.00 & 0.065 & 0.054 & 0.119 & 21 & 64 \\
\hline NBG-18 & medium-coarse & 1,600 & 1.86 & 2.02 & 0.044 & 0.048 & 0.092 & 17 & 12 \\
\hline \multicolumn{10}{|c|}{$\begin{array}{l}\text { (a) According to ASTM D } 8075-16^{36} \\
\text { (b)Information supplied by the manufacturer and from Chi, } \\
\text { (c) ORNL data from physical measurements according to A } \\
\text { (d) ORNL data obtained from helium pycnometry according } \\
\text { (e) Calculated using Eq. (3) } \\
\text { (f) Calculated as the difference between Eq. (4) and Eq. (3) } \\
\text { (g) Calculated using Eq. (4) } \\
\text { (h) Calculated as Vt } \times \rho_{\text {bulk }} \times 100 \% \\
\text { (i) From mercury porosimetry (see Section } 5.2)\end{array}$} \\
\hline
\end{tabular}

Other significant property is the nature of filler materials, which include petroleum products (e.g., NBG25, PCEA, IG-110) and coal-tar pitch (e.g., NBG-18, NBG-17). These graphites were manufactured via a variety of methods, such as vibrational molding (e.g., NBG-18, NBG-17), isostatic molding (e.g., 2020, 2114), isostatic pressing (e.g., IG-110), and extrusion (e.g., PCEA, CGB). Graphite grades AXF, ZXF, and TM are manufactured by POCO; PCEA and PGX are manufactured by GrafTech; NBG-25, NBG-17 and NBG-18 are manufactured by SGL; 2114 is manufactured by Mersen; IG-110 is manufactured by

\footnotetext{
${ }^{36}$ D8075-16, Standard Guide for Categorization of Microstructural and Microtextural Features Observed in Optical Microscopy of Graphite. ASTM International, 2016.

${ }^{37}$ S.-H. Chi, G.-C. Kim, and J.-H. Jang. "Effects of the Air Flow Rate on the Oxidation of NBG-18 and 25 Nuclear Graphite Grades," Trans. Korean Nuclear Society Spring Meeting, Jeju, Korea (May 10-11, 2007).
} 
Toyo Tanso; and ETU-10 is manufactured by Ibiden. For some graphites, the information on source materials and manufacturing procedures is proprietary (e.g., grades ZXF-5Q and AXF-5Q from POCO, grade ETU-10 from Ibiden). Graphite CGB from ORNL's MSRE was manufactured by Union Carbide from petroleum coke filler and coal-tar pitch as a binder by using the extrusion method and was pitchdensified by a nondisclosed procedure. This grade, which is no longer fabricated, was highly anisotropic and would be unsuitable under current standards and specifications ${ }^{38}$ for use in a reactor core. This document outlines strict isotropy index specifications for graphite grades that are appropriate for use as moderator or reflector blocks in the reactor core for which dimensional changes under neutron irradiation are a significant design consideration. However, CGB did fully satisfy the low-penetration requirement for molten salts and the low permeation of gaseous fission products specific to the MSRE.

\subsection{POROSITY CHARACTERIZATION FROM MERCURY POROSIMETRY}

Mercury porosimetry data for all 12 graphite grades are shown in Figure 4 and Figure 5. The plots show the cumulative volume of mercury intruded in graphite on the increase of mercury pressure and the volume extruded on the decrease of pressure. The results were assembled into two groups based on grain size (Table 1). The results for fine-, superfine-, ultrafine-, and microfine-grain graphites are shown in Figure 4, and the results for medium-fine-grain and medium-coarse-grain grades are shown in Figure 5.

${ }^{38}$ ASTM D7219-08 (reapproved 2014), Standard Specification for Isotropic and Near-Isotropic Nuclear Graphites. ASTM International, 2014. 

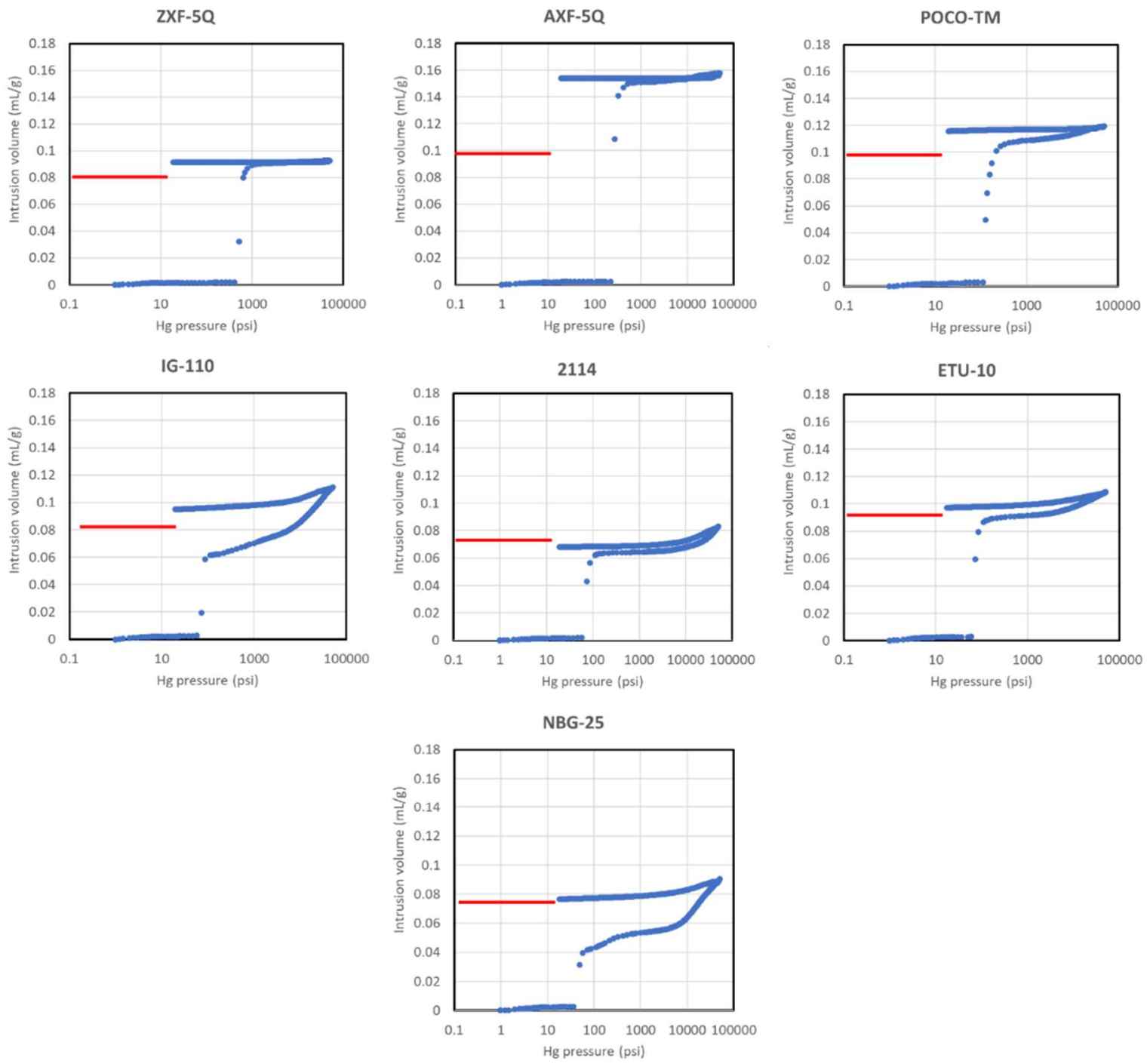

Figure 4. Mercury porosimetry results showing intrusion volume during the increase and decrease of mercury pressure for fine graphite grades. The open-pore volume calculated from Eq. (3) is indicated by a red line in each plot. 

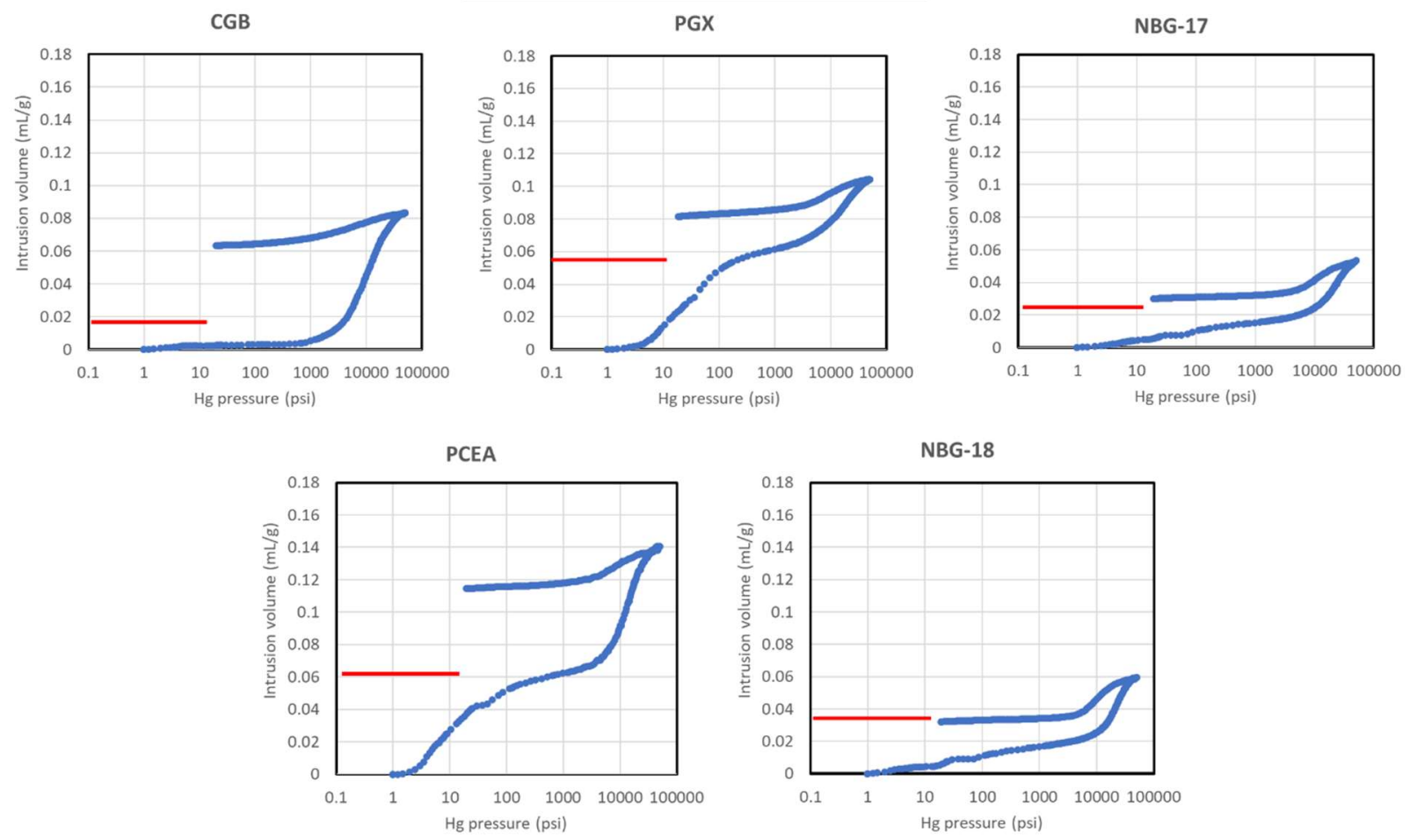

Figure 5. Mercury porosimetry results showing intrusion volume during the increase and decrease of mercury pressure for medium and coarse graphite grades. The open-pore volume calculated from Eq. (3) is indicated by a red line in each plot.

There is a significant difference between the mercury intrusion and extrusion cycles of the two graphite categories. All fine-grain graphites (Figure 4) show a sudden mercury intrusion (i.e., percolation) in a narrow, well-defined pressure interval, which indicates a narrow pore-size distribution. After percolation, the intrusion branch remains mostly flat on the increase in pressure (except for IG-110 and NBG-25), which shows that the open-pore volume capacity marked by red lines in the figures has been reached. On the release of pressure, mercury is not recovered from graphite pores, as observed for many other porous materials with large cavities interconnected by smaller pore throats. ${ }^{39}$

By contrast, medium- and coarse-grain graphites show a gradual mercury intrusion over a wide pressure interval, which indicates broadly distributed pore-size openings. Moreover, the intrusion branch shows a change of slope to a steeper slope at about $10,000 \mathrm{psia}(69 \mathrm{MPa})$, which might be interpreted as additional intrusion in very fine pores; however, studies ${ }^{40,41}$ indicate that this change of slope at these high mercury pressures indicates irreversible structural changes caused by external pressure that exceeds the graphite mechanical strength, which creates a path to the previously closed porosity or newly created porosity.

Theoretically, the highest possible volume of mercury that can intrude the graphite sample before any structural damage occurs should be equal or very close to the volume of open pores $\left(V_{0}\right)$, as calculated by Eq. (3), from bulk and skeletal density values and listed in Table 1. This calculated volume of open pores

${ }^{39} \mathrm{P}$. A. Webb. An Introduction to the Physical Characterization of Materials by Mercury Intrusion Porosimetry with Emphasis on Reduction and Presentation of Experimental Data. Micromeritics Instrument Corp., January 2001.

https://www.micromeritics.com/pdf/app articles/mercury paper.pdf (accessed March 12, 2020).

${ }^{40}$ J. M. Dickinson and J. W. Shore. "Observations Concerning the Determination of Porosities in Graphites," Carbon 6 (1968): 937-941.

${ }^{41}$ D. J. Baker and J. B. Morris. "Structural Damage in Graphite Occurring during Pore Size Measurements by High Pressure Mercury,” Carbon 9 (1971): 687-690. 
is marked with a red line in each plot in Figure 4 and Figure 5. The saturation of open pores coincides with the flattening of the curve for most fine-grain graphite grades, except for grade AXF-5Q, and with the inflection point for medium- and coarse-grain graphites. Graphite grades IG-110 and NBG-25 show a combination of behavior with a sharp percolation, followed by gradual uptake before a change of slope, indicating structural damage, as previously reported by others for IG-110. ${ }^{42}$

To better visualize the differences between the graphite grades, an overlay plot is shown Figure 6 . The plot emphasizes the differences between fine-grain graphites, with clear mercury percolation in a narrow pressure interval, and medium-grain graphites, which are penetrated by mercury starting from the lowest pressures. Moreover, the structural damage caused by high pressure in medium-grain graphites is emphasized by the change of slope in intrusion curves when mercury pressure approaches or exceeds 10,000 psia.

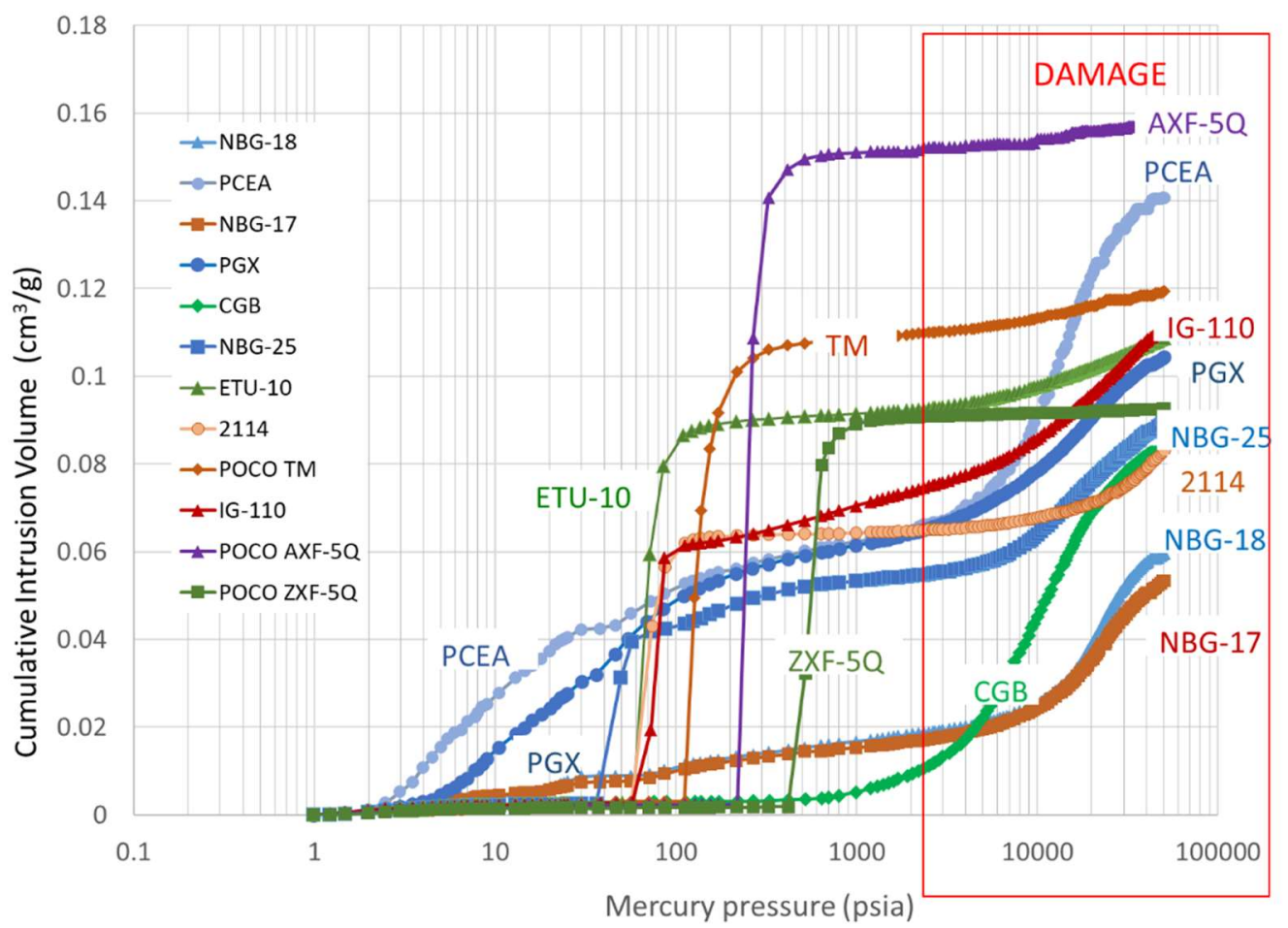

Figure 6. Cumulative volume of mercury intrusion vs. mercury pressure for all graphite grades. The range at which excessive mercury pressure is likely to have caused structural damage is marked with a red rectangle.

The pore distribution of all graphite grades obtained from mercury porosimetry is shown in Figure 7 as $d\left(V_{\mathrm{Hg}}\right) / d \log (d)$, where $V_{\mathrm{Hg}}$ is the volume of intruded mercury $\left(\mathrm{cm}^{3} \mathrm{~g}^{-1}\right)$, and $d$ is the pore diameter $(\mu \mathrm{m})$. The differences between fine-grain and medium-grain graphites are observed clearly in this figure. Finegrain graphites exhibited unimodal pore-size distribution with a unique, well-defined diameter or pore openings. Medium- and coarse-grain graphites exhibited a broad distribution of pore sizes and are more susceptible to structural damage at higher mercury pressure.

\footnotetext{
${ }^{42}$ K. L. Jones, G. M. Laudone, and G. P. Matthews. "A Multi-Technique Experimental and Modelling Study of the Porous Structure of IG-110 and IG-430 Nuclear Graphite,” Carbon 128 (2018): 1-11.
} 


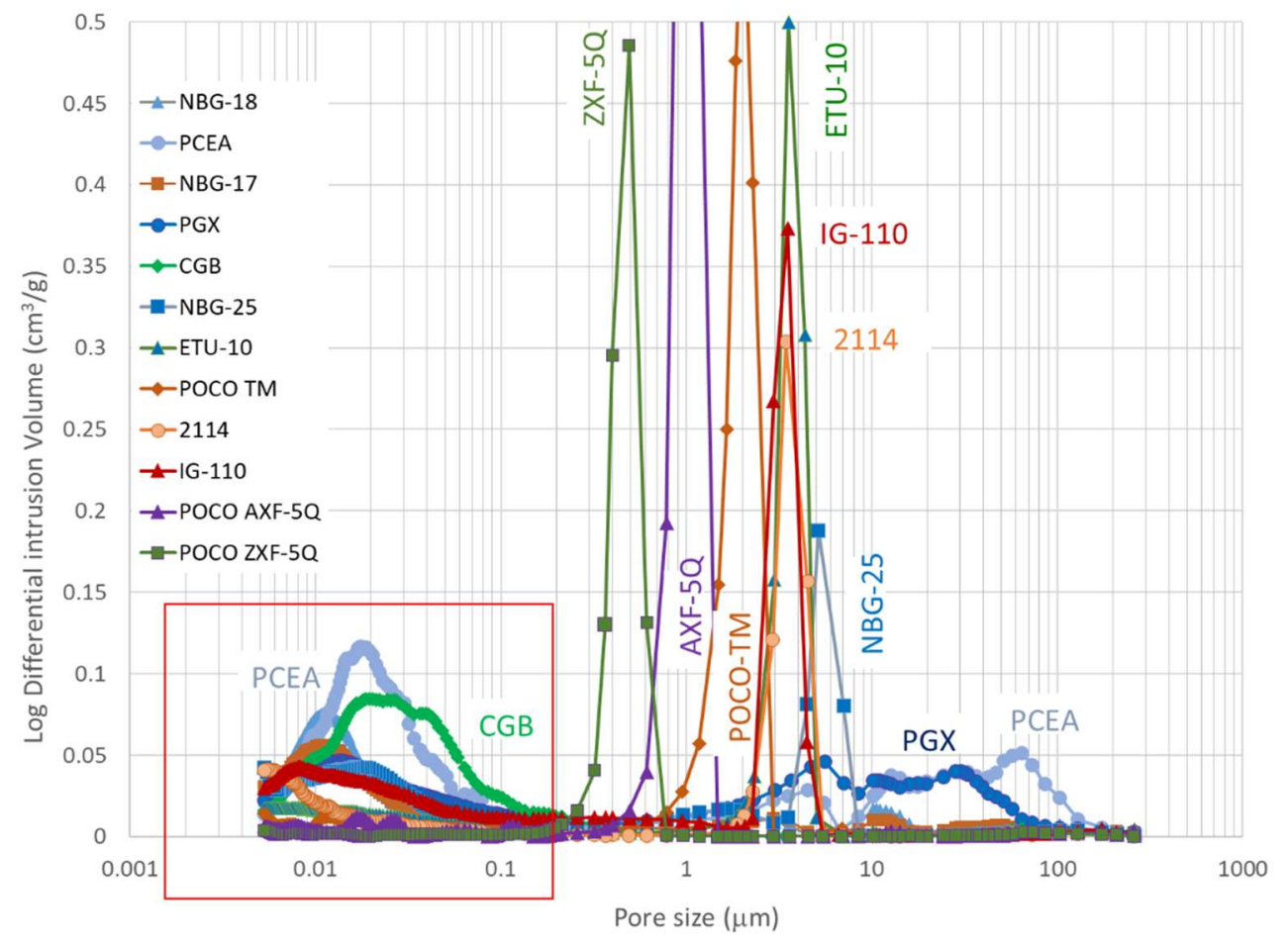

Figure 7. Log differential pore volume vs. pore diameter for all graphite grades. The range at which excessive mercury pressure is likely to have caused structural damage is marked with a red rectangle.

The pore diameters for all graphite grades are shown in Table 1. As expected, a relationship between graphite grain size and open-pore diameter is observed, although the dependence is not linear. Additionally, the results show that only two POCO graphite grades, AXF-5Q and ZXF-5Q, have pore openings that are less than $1 \mu \mathrm{m}$ in diameter, as does the CGB grade, which is the graphite used in ORNL's MSRE; however, POCO grades have larger volumes of open pores.

\subsection{RESULTS FROM INTRUSION TESTING WITH MOLTEN FLINAK}

Six of the graphite grades listed in Table 1 were selected for the initial testing and commissioning of the salt intrusion system using FLiNaK. The graphite selection covered a range of pore-size distributions based on mercury porosimetry and covered grades of interest to collaborators. The six grades selected for testing were NBG-18, PCEA, NBG-25, ETU-10, 2114, and IG-110. The pore-volume properties from mercury porosimetry for these six grades are shown in Figure 8. 

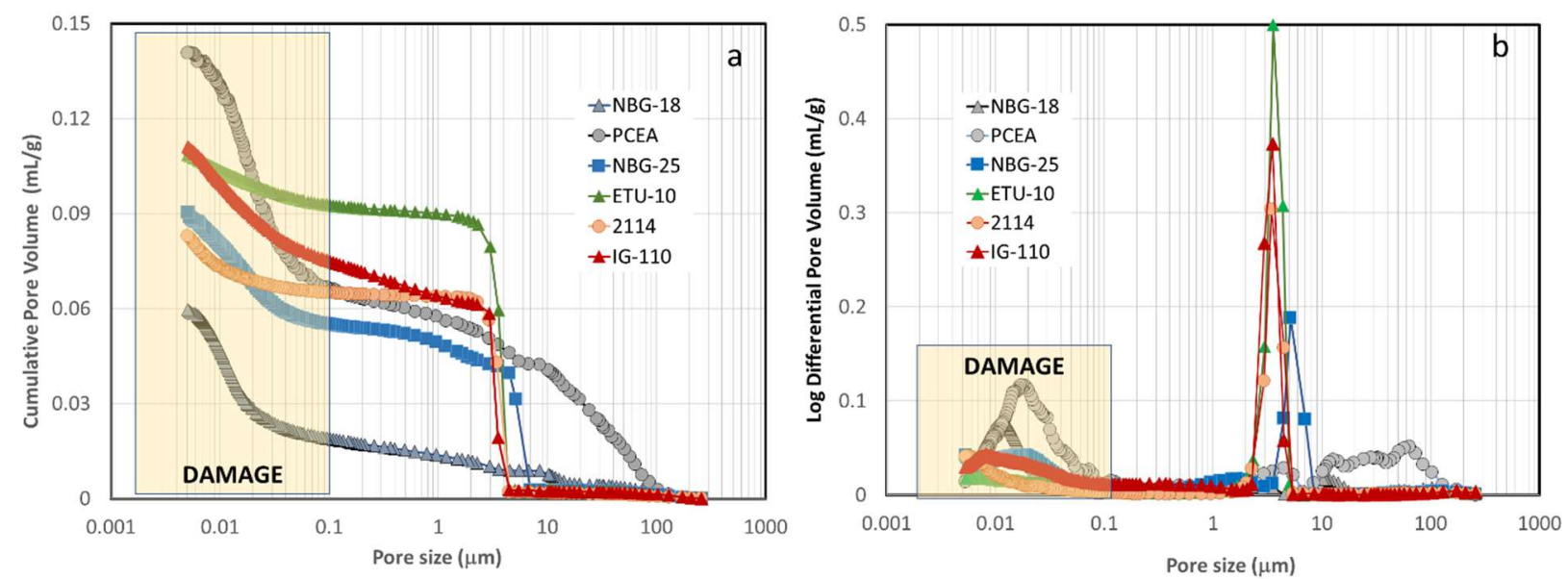

Figure 8. Pore volume distribution of six graphite grades measured by mercury porosimetry: (left) cumulative pore volume vs. pore size; (right) log differential pore volume vs. pore size.

An intrusion test was performed with these six graphite grades by using FLiNaK at $750^{\circ} \mathrm{C}$ and $101 \mathrm{psig}$ $(798 \mathrm{kPa})$; pressure and temperature were held constant for $12 \mathrm{~h}$. The specimens' weight before $\left(w_{l}\right)$ and after $\left(w_{2}\right)$ the experiment was measured in a glovebox. The specific net weight increase $(\mathrm{g}$ salt $/ \mathrm{g}$ graphite $)$ was converted into the volume of molten salt impregnated in graphite $\left(\mathrm{cm}^{3} / \mathrm{g}\right)$ by using the density of molten FLiNaK $\left(\mathrm{g} / \mathrm{cm}^{3}\right)$ at the experiment temperature $\left(750^{\circ} \mathrm{C}\right)$. The density of the molten salt was estimated from the following relationship reported by Sohal et al., ${ }^{43}$ Vriesema, ${ }^{44}$ Ingersoll et al. ${ }^{45}$ and Williams et al. ${ }^{46}$ :

$$
\rho_{\text {FLiNaK }}=2,729.3-0.73 T
$$

where $T$ is the absolute temperature (K). This density relationship has an uncertainty of $\pm 2 \%$ at temperatures between 667 and $987^{\circ} \mathrm{C}$. For the test temperature $\left(750^{\circ} \mathrm{C}\right)$, a density value of $1.982 \mathrm{~g} / \mathrm{cm}^{3}$ is obtained for FLiNaK. With this result and by using the specific properties of each graphite grade from Table 1, the parameters $D_{0}$ and $D_{1}$ defined by ASTM D8091-16 were calculated and listed in Table 2. The values of parameter $D_{0}$ indicate that for the conditions of the test, FLiNaK infiltrated $65-81 \%$ of the available open-pore volume; additionally, the $D_{0}$ values are all less than the unity, indicating that no damage to the graphite structure occurred at the testing conditions.

\footnotetext{
${ }^{43}$ M. S. Sohal, M. A. Ebner, P. Sabharwall, and P. Sharpe. Engineering Database of Liquid Salt Thermophysical and Thermochemical Properties. INL/EXT-10-18297, March 2010.

${ }^{44}$ I. B. Vriesema. Aspects of Molten Fluorides as Heat Transfer Agents for Power Generation. Report WTHD No. 112, Delft University of Technology, Delft, Netherlands (1979).

${ }^{45}$ D. T. Ingersoll, C. W. Forsberg, and P. E. MacDonald. Trade Studies on the Liquid-Salt-Cooled Very-High-Temperature Reactor: Fiscal Year 2006 Progress Report. ORNL/TM-2006/140, Oak Ridge National Laboratory (2006).

${ }^{46}$ D. F. Williams and L. M. Toth. Chemical Considerations for the Selection of the Coolant for the Advanced High-Temperature Reactor. ORNL/GEN4/LTR-05-011, Oak Ridge National Laboratory, September 2005.
} 
Table 2. Results obtained from FLiNaK intrusion experiment at $750^{\circ} \mathrm{C}, 101 \mathrm{psig}(798 \mathrm{kPa})$, and $12 \mathrm{~h}$.

\begin{tabular}{|c|c|c|c|c|c|c|c|}
\hline \multirow{2}{*}{$\begin{array}{l}\text { Specimen } \\
\text { ID }\end{array}$} & \multirow{2}{*}{$\begin{array}{c}\text { Graphite } \\
\text { grade }\end{array}$} & \multirow{2}{*}{$\begin{array}{l}\text { Weight } \\
\text { before } \\
\text { intrusion } \\
\text { (g) }\end{array}$} & \multirow{2}{*}{$\begin{array}{l}\text { Weight } \\
\text { after } \\
\text { intrusion } \\
\text { (g) }\end{array}$} & \multirow{2}{*}{$\begin{array}{c}\text { Weight } \\
\text { uptake } \\
(\%)\end{array}$} & \multirow{2}{*}{$\begin{array}{c}\text { Intrusion } \\
\text { volume } \\
\left(\mathrm{cm}^{3}{ }_{\text {salt }} / \mathrm{g}\right)\end{array}$} & \multicolumn{2}{|c|}{ ASTM parameters } \\
\hline & & & & & & $\mathbf{D}_{0}$ & $\mathbf{D}_{1}$ \\
\hline B4 & NBG-18 & 2.6715 & 2.8215 & 5.6 & 0.028 & 0.65 & 0.31 \\
\hline D4 & PCEA & 2.5483 & 2.7797 & 9.1 & 0.046 & 0.71 & 0.39 \\
\hline M4 & NBG-25 & 2.6064 & 2.8463 & 9.2 & 0.046 & 0.69 & 0.44 \\
\hline U4 & ETU-10 & 2.4994 & 2.8515 & 14.1 & 0.071 & 0.81 & 0.55 \\
\hline T4 & 2114 & 2.6067 & 2.8688 & 10.1 & 0.051 & 0.71 & 0.48 \\
\hline $\mathbf{E} 4$ & IG-110 & 2.5276 & 2.7993 & 10.7 & 0.054 & 0.69 & 0.45 \\
\hline
\end{tabular}

Based on the weight uptake of the samples, the fine-grain graphites had a larger increase in weight than the medium- and coarse-grain graphites. ETU showed that the highest overall uptake was $14.1 \%$, whereas NBG-18 showed that the lowest uptake was 5.6\%. Similar results have been reported in the literature, particularly in the report from He et al., ${ }^{47}$ which included three of the same grades used in this study, namely NBG-18, 2114, and IG-110. Although the temperature and duration of impregnation reported in He et al. $\left(650^{\circ} \mathrm{C}\right.$ and $\left.20 \mathrm{~h}\right)$ were slightly different than the ones used in this study $\left(750^{\circ} \mathrm{C}\right.$ and $\left.12 \mathrm{~h}\right)$, the pressure range covered is similar. Figure 9 compares the results in He et al. with the results from this study. Although there are differences in the magnitude of the uptake likely due to the differences in experimental conditions, the overall trend between the grades is the same in both studies.

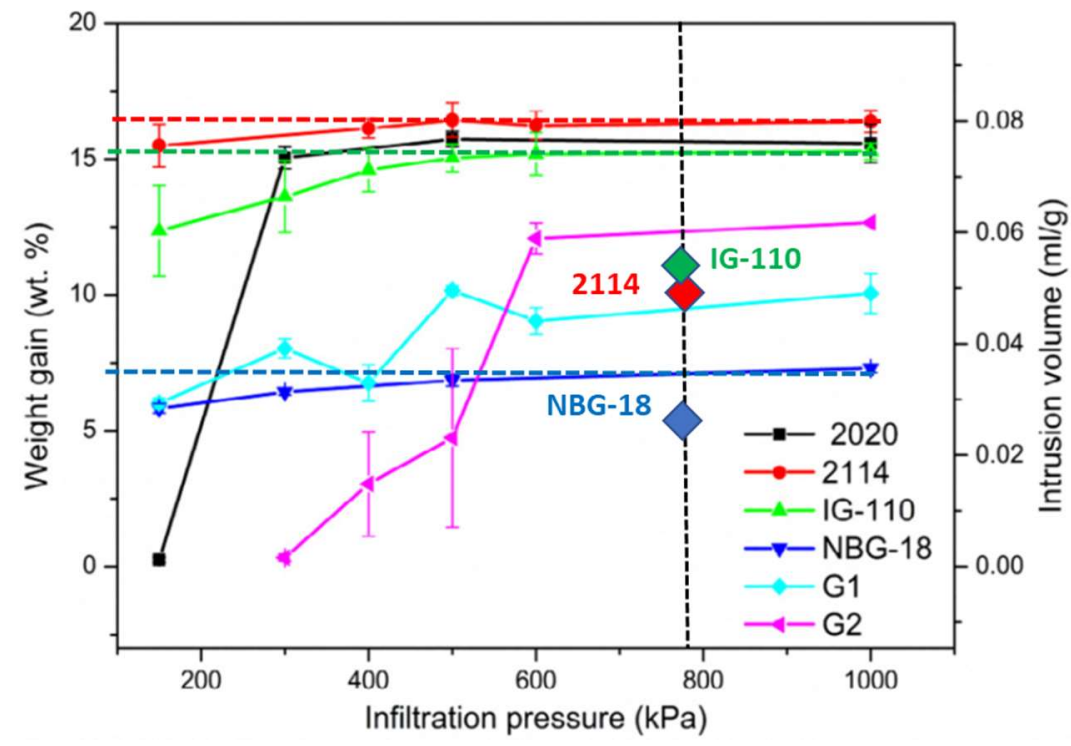

Figure 9. FLiNaK impregnation results from this study at $750^{\circ} \mathrm{C}$ and $798 \mathrm{kPa}$ for $12 \mathrm{~h}$ (large diamond symbols) compared with published data for FLiNaK impregnation at $650^{\circ} \mathrm{C}$ for $20 \mathrm{~h}$ up to $1,000 \mathrm{kPa}$ (adapted from He et al. $^{47}$ ).

${ }^{47}$ Z. He, L. Gao, W. Qi, B. Zhang, X. Wang, J. Song, X. He, C. Zhang, H. Tang, H. Rohan, H. Xia, and X. Zhou. "Molten FLiNaK Salt Infiltration Intro Degassed Nuclear Graphite under Inert Gas Pressure,” Carbon 84 (2015): 511-518. 


\subsection{CORRELATION BETWEEN FLINAK IMPREGNATION AND MERCURY INTRUSION}

As described previously, the Washburn equation in Eq.( 5) defines the relationship between the pressure differential $(P)$ required for pushing a given fluid in capillary tubes (assumed right cylinders) of diameter $(d)$, given the fluid properties, namely surface tension $(\gamma)$ and wetting angle $(\theta)$ at the liquid-solid interface. Therefore, it is possible to establish a parallel between the behavior of a sample with a given pore-size distribution with various fluids if the surface tension and wetting angle are known for all fluids This was emphasized early by the MSRE scientists who showed that the mercury intrusion results could be compared with the salt impregnation results if proper wetting parameters were used for graphitemolten salt and graphite-mercury systems. For example, they found that volume permeation by mercury at $485 \mathrm{psia}(3.34 \mathrm{MPa}$ ) and at room temperature is equal to or greater than permeation by fuel salts (LiF$\left.\mathrm{BeF}_{2}-\mathrm{ThF}_{4}-\mathrm{UF}_{4} ; 67-18.5-14-0.5 \mathrm{~mole} \%\right)$ at $165 \mathrm{psia}(1.14 \mathrm{MPa})$ and $700^{\circ} \mathrm{C}$. Therefore, mercury porosimetry was recommended at the time as a material preselection test to be used mostly for quality control by graphite manufacturers. ${ }^{4}$

By solving the Washburn equation for the diameter of the capillary, a relationship between the two solid/liquid systems (i.e., graphite-mercury and graphite-salt) could be rewritten as follows:

$$
d=\frac{4 \gamma_{\text {salt }} \cos \text { graphite-salt }}{P_{\text {salt }}}=\frac{4 \gamma_{H g} \cos \theta_{\text {graphite }-H g}}{P_{H g}}
$$

which then leads to the following relation between the pressure scale for salt impregnation with the pressure scale for mercury intrusion:

$$
\log P_{\text {salt }}=\log P_{H g}+\log \left(\frac{\gamma_{\text {salt }} \cos \theta_{\text {graphite-salt }}}{\gamma_{H g} \cos \theta_{\text {graphite }-H g}}\right),
$$

which can be used to estimate the penetration amount of molten salts if the properties - surface tension $(\gamma)$ and wetting contact angle $(\theta)$ - of the specific graphite-salt and graphite-mercury systems are known.

In this study, mercury porosimetry measurements were conducted at room temperature $\left(25^{\circ} \mathrm{C}\right)$ and FLiNaK intrusion tests were performed at $750^{\circ} \mathrm{C}$. A review of the literature shows the parameters listed in Table 3 for these two systems.

Table 3. Surface tension and contact angles for the graphite-mercury and graphite-FLiNaK systems.

\begin{tabular}{|l|c|c|}
\hline & $\begin{array}{c}\text { Surface tension }(\gamma) \\
(\mathbf{N} / \mathbf{m})\end{array}$ & $\begin{array}{c}\text { Contact angle }(\theta) \\
\left({ }^{\circ}\right)\end{array}$ \\
\hline Mercury $(\mathrm{Hg})$ at $25^{\circ} \mathrm{C}^{35}$ & $0.485 \mathrm{~N} / \mathrm{m}$ & -- \\
\hline FLiNaK at $750^{\circ} \mathrm{C}^{43,47}$ & $0.169 \mathrm{~N} / \mathrm{m}$ & -- \\
\hline Hg-graphite at $25^{\circ} \mathrm{C}^{35}$ & -- & $155^{\circ}$ \\
\hline FLiNaK-graphite at $750^{\circ} \mathrm{C}^{43,47}$ & -- & $135^{\circ}$ \\
\hline
\end{tabular}

By applying the parameters in Table 3 to solve Eq. (8), the following pressure conversion factor is calculated and valid for $\mathrm{FLiNaK}$ at $750^{\circ} \mathrm{C}$ and $\mathrm{Hg}$ at $25^{\circ} \mathrm{C}$ :

$$
P_{\text {FLiNaK }}=0.2716 \times P_{H g} .
$$


By using this relationship, the cumulative mercury intrusion plots (Figure 6) for the six graphite grades selected were used to calculate the equivalent cumulative plots on the pressure scale for FLiNaK, as shown in Figure 10.

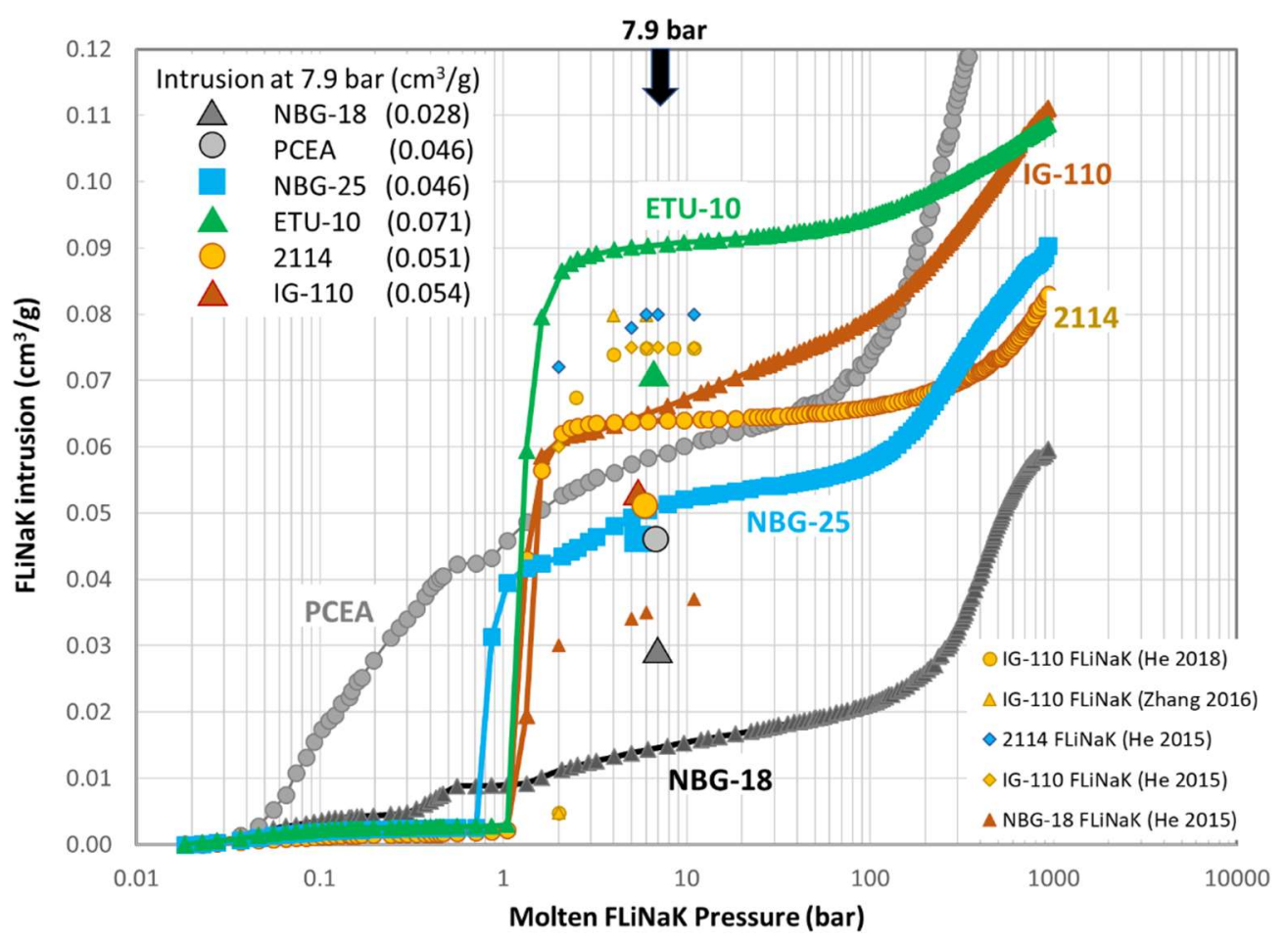

Figure 10. Predicted FLiNaK impregnation as a function of pressure at $750^{\circ} \mathrm{C}$ based on mercury porosimetry data. Experimental data from intrusion tests at $750^{\circ} \mathrm{C}$ for $12 \mathrm{~h}$ are overlaid (large symbols). Other literature values for similar systems (small symbols) are also added. (Published sources: He $2018,{ }^{26} \mathrm{He} 2015,{ }^{47}$ Zhang 2016.48) The upper left corner shows the legend for this work's results and the corresponding impregnated FLiNaK volumes.

The results from the intrusion testing at $750^{\circ} \mathrm{C}, 7.9 \mathrm{bar}(101 \mathrm{psig})$, for $12 \mathrm{~h}$ (Table 2) are also plotted in Figure 10. Additionally, several other FLiNaK impregnation results from the literature ${ }^{26,48,47}$ were also added to the figure. These data are provided for qualitative comparison only because the impregnation conditions were slightly different (i.e., lower temperature and longer time at pressure).

The pressure scale of salt impregnation experiments is conveniently expressed in psig units relative to the atmospheric pressure, whereas the mercury intrusion measurements use the absolute psia units relative to absolute vacuum. The two scales must be correlated with the relationship $P(\mathrm{psia})=P(\mathrm{psig})+14.69$, where $14.69 \mathrm{psi}=1 \mathrm{~atm}=101.325 \mathrm{kPa}$. In the following discussion, the absolute pressure scale with the reference point at absolute vacuum will be used. The intrusion data from other publications in Figure 9, which were measured with graphite evacuated in situ down to 5-6 Pa before submersion in molten salt, did not need to be rescaled.

The primary conclusion from the results presented in Table 2 and Figure 10 is that significant intrusion of molten FLiNaK is observed at the testing conditions for all six graphite grades, and this was expected based on the physical properties of the graphites, showing significant volume of open pores, and on

${ }^{48}$ W.-T. Zhang, B.-L. Zhang, J.-L. Song, W. Qi, X.-J. He, Z.-J. Liu, P.-F. Lian, Z.-T. He, L.-N. Gao, H.-H. Xia, Z.-D. Liu, X.-T. Zhou, L.-B. Sun, and X.-X. Wu. "Microstructure and Molten Salt Impregnation Characteristics of a Micro-Fine Grain Graphite for Use in Molten Salt Reactors," New Carbon Mat. 31 (2016): 585-593. 
mercury porosimetry results, showing large pore opening diameters. This showed that all graphite grades tested had pore openings larger than $3 \mu \mathrm{m}$, which are too large to oppose FLiNaK impregnation at 7.9 bar absolute pressure.

Early MSRE calculations determined that the pore openings of graphite must be reduced to below $1 \mu \mathrm{m}$ in diameter to withstand molten salt impregnation at MSRE project conditions. Although MSRE conditions and salts were different from those of the present experiment, the differences are too small to challenge the MSRE specification on acceptable graphite pore openings that would render graphite impervious to salt penetration. For comparison, the CGB graphite used in MSRE had a significant portion of accessible void entrances less than $0.4 \mu \mathrm{m}$ in diameter. Calculations that use the Washburn equation show that a differential pressure larger than 300 psia (20.7 bar) would be required to force the MSRE fuel salt into these voids. Impregnation tests have supported this prediction. ${ }^{49}$

\subsection{LIMITATIONS OF THE PREDICTIONS BASED ON MERCURY POROSIMETRY}

Mercury intrusion porosimetry is a well-established analytical technique for fully characterizing the porosity of various classes of materials. It is supported by internationally recognized standard procedures for testing and data analysis. Several specialized testing laboratories can execute the tests in a few days. Therefore, it is more convenient for those interested in developing, testing, and manufacturing new graphite grades for MSRs to use mercury intrusion porosimetry as a rapid and convenient test, at least for the selection and production phases. The results, along with numerous literature references cited previously, demonstrate that pressure-driven mercury porosimetry can be used as an indication for the behavior of molten salt impregnation at equivalent pressures. However, there are a few limiting issues, such as the reliability of parameters and the source of errors, that must be clarified first.

The reliability of the correlation between mercury intrusion data and molten salt impregnation behavior depends on the accuracy of available information on surface tension and contact angle for particular molten salt-graphite grades.

There are several information sources for the surface tension of common molten salt composition with potential nuclear applications. Generally, surface tension decreases with the increase of temperature. For several systems of interest for MSR projects, the variation was quantified by several equations available in the comprehensive review by Sohal et al. ${ }^{43}$ and in the literature cited therein. Information is now available on the temperature variation of surface tension of several molten salts of interest for MSR projects ${ }^{.50,51}$ Alternatively, they can be calculated from thermodynamic databases. ${ }^{52,53}$ Information on

\footnotetext{
${ }^{49}$ R. P. Briggs. Molten-Salt Reactor Program Semiannual Progress Report for Period Ending July 31, 1964. ORNL-TM-3708, Oak Ridge National Laboratory, November 1964.

${ }^{50}$ M. V. Smirnov and V. P Stepanov. "Density and Surface Tension of Molten Alkali-Halides and Their Binary Mixtures," Electrochim Acta 27 (1982): 1,551-1,563.

${ }^{51}$ G. J. Janz and R. P. T. Tomkins. "Molten Salts vol. 5.1, Additional Single and Multiple Component salt Systems; Electrical Conductance, Density, Viscosity, and Surface Tension Data," J Phys Chem Ref Data 9 (1980): 831-1,021.

${ }^{52}$ G. J. Janz, G. R. Lakshimanayanan, R. P. T. Tomkins, and J. Wong. “Surface Tension Data,” in Molten Salts Vol. 2, US Department of Commerce, NSRDS-NBS-28 (1969).

${ }^{53}$ T. Tanaka, K. Hack, T. Iida, and S. Hara. "Application of Thermodynamic Databases to the Evaluation of Surface Tensions of Molten Alloys, Salt Mixtures and Oxide Mixtures," Z Metallkunde 87 (1996): 380-389.
} 
wetting behavior ${ }^{54}$ and the contact angle of various salts on graphite is still scarce, but a few reports are available..$^{47,55,56}$

More uncertain are the values of contact angles for specific salt and/or graphite systems. Recent measurements for FLiBe and FLiNaK on graphite IG-110 found large variations as a function of temperature and conditions of graphite surface ${ }^{56}$. More recent data from two different laboratories ${ }^{47,56}$ found fair agreement for the wetting angle of FLiNaK on IG-110 at $600^{\circ} \mathrm{C}$. This result $\left(\theta=135^{\circ}\right)$ was used for all graphite grades in the calculations. The contact angle varies little with temperature, but it is strongly affected by chemical composition in mixed salts and usually decreases in time. ${ }^{55}$ When measured on graphite, contact angles were strongly irreproducible if graphite were degassed at room temperature (even though at $10^{-5}$ Torr). However, degassing at $1,000-1,100^{\circ} \mathrm{C}$, even at lower vacuum $10^{-3}$ Torr, produced stable contact angles readings. ${ }^{55}$ More fluctuations and unwanted differences between advancing and receding angles were found if salt purity were not well controlled. The stability criterion for contact angle measurements is that changes in time are less than $3^{\circ}$ per minute. ${ }^{55}$

\footnotetext{
${ }^{54}$ W. R. Grimes. Reactor Chemistry Division Annual Progress Report for Period Ending January 31, 1964, ORNL-3591, Oak Ridge National Laboratory, 1964.

${ }^{55}$ C. F. Morel. Surface Tensions of Molten Salts and Contact Angle Measurements of Molten Salts on Solids. EUR 4482, Euratom (1970).

${ }^{56}$ A. R. Delmore, W. Derdeyn, R. Gakhar, and E. O. Scarlat. "Wetting of Graphite by Molten Salts: Initial Experiments," Trans. American Nuclear Society 118 (2018): 121-124.
} 


\section{CONCLUSION AND FUTURE WORK}

ORNL designed and built a test rig for the molten salt impregnation of graphite in controlled conditions; the system can operate up to 10 bars at $750^{\circ} \mathrm{C}$. After commissioning tests, six graphite grades of various origins, raw materials, grain sizes, and microstructures were selected for the impregnation test using FLiNaK at $750^{\circ} \mathrm{C}$ and $101 \mathrm{psi}$. The FLiNaK impregnation test produced results in good correlation with the expectations based on graphite microstructure, including open pore volume, and also based on other results published in the open literature.

Additionally, mercury intrusion porosimetry measurements were performed on samples from the same six graphite grades and six other grades available, representing a wider range of graphite properties. The results revealed significant differences between the size distribution of pore openings and correlations with graphite microstructure. Furthermore, it was also shown that salt impregnation data can be correlated with mercury intrusion data if the correct wetting characteristics of the graphite-salt system are known.

The results support earlier suggestions from the time of the MSRE that mercury intrusion porosimetry should be used to rapidly assess the percolation mode and the associated diameter of pore openings in various graphite grades. These properties are relevant to the molten salt impregnation behavior.

However, more experimental data are needed for the various graphite-salt systems before mercury intrusion porosimetry could be recommended as a facile and rapid technique for quickly identifying graphite grades suitable for use in MSR applications. Data collection should include more measurements over a broader pressure range and variable intrusion times and temperature. These measurements will reveal more details on the threshold pressure that prompt penetration and the pressure-dependent saturation curve, thus defining the range of operation conditions for selected MSR designs. The data should then be compared with predictions based on the Washburn equation and porosity distribution from mercury porosimetry, including wetting parameters (i.e., surface tension and contact angle) that are appropriate for the selected graphite-salt system.

Efforts should also be directed toward obtaining more accurate measurements of the contact angle for the various graphite-salt systems and a better understanding of external factors that can affect wetting, such as temperature, graphite surface roughness, environmental humidity, and oxygen content.

In addition to understanding the impregnation behavior of molten in graphites, there are many outstanding questions that remain unresolved, regarding the chemical interactions of the salt with the graphite and the effect on the microstructure and properties of the salt-exposed graphite; some of these questions are listed as follows:

- How deep do the various ions in molten salts (e.g., Li, $\mathrm{Na}, \mathrm{K}$ ) penetrate into the graphite? How does this vary as a function of salt temperature, pressure, and contact time of exposure? Do penetration depth, time, and temperature data relationships follow Fick's diffusion laws?

- How is the diffusion of molten salt ions affected by the microstructure of various graphite grades (e.g., microfine-grain grades vs. ultrafine-grain grades)?

- Do molten salt ions bond with the graphite structure? If so, what is the effect of the chemical bonding (e.g., fluorination leading to development of new $>$ C-F bonds) on graphite properties? How much is the local structure affected by these chemical changes, and what is the impact on mechanical strength, irradiation behavior, and metal component corrosion in electrochemical contact with chemically modified graphite? 
- What is the effect of salt phase changes in graphite pores (i.e., solidification followed by melting on thermal cycles) on the graphite structural integrity and mechanical and thermal properties?

- How much of the impregnated salt is irreversibly locked in graphite pores and cannot be retrieved by depressurization at temperatures above the melting point of bulk molten salt?

- Do graphite impurities or the chemistry of ambient atmosphere (e.g., humidity and oxygen content) change the wetting properties and impregnation behavior? If so, by how much? Are these changes irreversible?

The ORNL salt impregnation system described in this report will generate not only data on intrusion behavior but also a wide range of salt-impregnated graphite samples that will be further analyzed with advanced characterization techniques (i.e., LIBS, XRD, Raman, SEM-EDX, and GDMS) to help answers some of these outstanding questions.

The results presented here, and future results obtained with this system, are expected to help advance the understanding of factors that control the extent of salt penetration in graphite and the relationship with intrinsic structural properties of various grades. Together, correlating direct measurements results and graphite structural properties should allow a predictable model to be developed that could be used for the selection and qualification of optimal graphite grades, which are tailored to design-operation conditions and molten salt properties. 